\title{
Las personas mayores de América Latina en la era digital: superación de la brecha digital ${ }^{1}$
}

\author{
Guillermo Sunkel y Heidi Ullmann
}

\section{Resumen}

En los últimos decenios, la población de América Latina entró en un proceso de envejecimiento sostenido. Los cambios relacionados con el auge de la sociedad digital han transformado profundamente la manera en que los habitantes de la región interactúan entre sí y con sus Gobiernos. En este artículo se analiza el uso y la apropiación de las tecnologías digitales por parte de las personas mayores en la región. Se describe la evolución del uso que hacen de Internet, utilizando datos de las encuestas de hogares de los respectivos países. Se examinan los factores determinantes del uso de Internet entre las personas mayores, teniendo en cuenta variables como el sexo, el origen étnico, el nivel educativo y la residencia rural o urbana mediante análisis de regresión logística, y se destacan las políticas y los programas para promover la inclusión de las personas mayores mediante el uso de tecnologías digitales.

\section{Palabras clave}

Envejecimiento, ancianos, Internet, tecnología de la información, tecnología de las comunicaciones, brecha digital, alfabetización en materia de computación, encuestas de hogares, programas de acción, indicadores TIC, América Latina

\section{Clasificación JEL}

I31, 035, J14

\section{Autores}

Guillermo Sunkel es Oficial de Asuntos Sociales de la División de Desarrollo Social de la Comisión Económica para América Latina y el Caribe (CEPAL) y tiene un doctorado en Estudios Culturales de la Universidad de Birmingham. Correo electrónico: guillermo.sunkel@cepal.org.

Heidi Ullmann es Oficial de Asuntos Sociales de la División de Desarrollo Social de la Comisión Económica para América Latina y el Caribe (CEPAL) y tiene un doctorado en Asuntos Públicos de la Universidad de Princeton. Correo electrónico: heidi. ullmann@cepal.org.

\footnotetext{
Los autores desean reconocer las contribuciones de Leydi Hernández, quien en 2015 terminó una pasantía en la Comisión Económica para América Latina y el Caribe (CEPAL) bajo la supervisión de Guillermo Sunkel. Este artículo se basa, en gran medida, en el trabajo que Hernández llevó a cabo en la CEPAL. Los autores también desean reconocer a Raymundo Mogollón por su apoyo con el procesamiento de datos.
} 


\section{Introducción}

En los últimos decenios, los países de América Latina han entrado en un proceso de envejecimiento sostenido de la población. Los pronunciados descensos en las tasas de fecundidad - que han ido acompañados de mejoras en la esperanza de vida - han modificado sustancialmente la estructura etaria de la población, con un considerable aumento de la proporción de personas mayores ${ }^{2}$. Las Naciones Unidas estiman que para 2050 las personas mayores representarán aproximadamente una cuarta parte de toda la población de la región (véase el gráfico 1). De conformidad con la definición establecida en la Convención Interamericana sobre la Protección de los Derechos Humanos de las Personas Mayores (OEA, 2015), para los fines del presente estudio se define la población adulta mayor como las personas de 60 años o más.

\section{Gráfico 1}

América Latina y el Caribe: población por grupos etarios, 1985-2060

(En millones de personas)

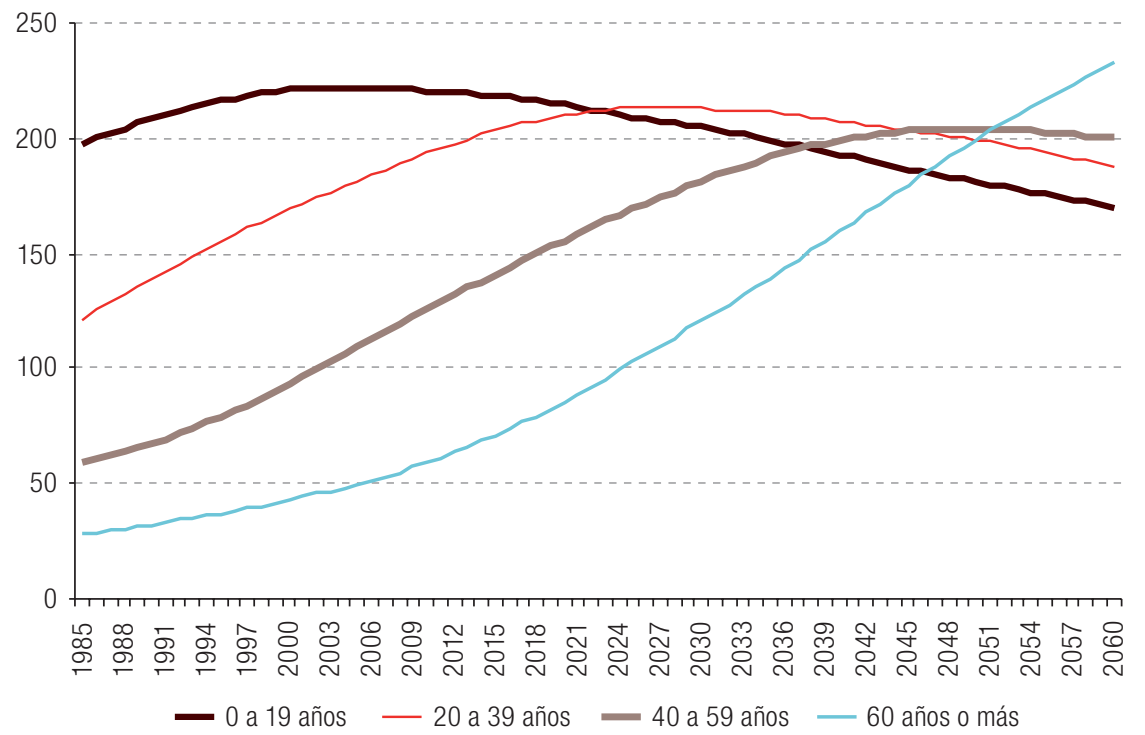

Fuente: Naciones Unidas, World Population Prospects. The 2015 Revision (ESA/P/WP.241), Nueva York, 2015.

Esta tendencia, sin embargo, exhibe cierta heterogeneidad regional, dado que el proceso de envejecimiento no ha tenido la misma intensidad en todos los países de América Latina y el Caribe. En el cuadro 1 se presentan cuatro grupos de países. El primer grupo (siete países) tiene niveles relativamente altos de fecundidad (más de 3,3 hijos por mujer) y un índice de envejecimiento de menos de 17 personas mayores por cada 100 menores de 15 años. Estos países se encuentran en lo que la CEPAL ha denominado la etapa incipiente del proceso de transición demográfica. El segundo grupo está formado por 15 países con tasas de fecundidad más bajas (entre 2,3 y 3 hijos por mujer) e índices de envejecimiento que oscilan entre 19,8 y 31,9, lo que significa que están en la etapa moderada del proceso de envejecimiento. Los tres países que integran el tercer grupo se encuentran en una etapa de envejecimiento de moderada a avanzada, ya que sus tasas de fecundidad varían entre 1,7 y 2,5 hijos por mujer y los índices de envejecimiento oscilan entre 32,8 y 51 personas mayores por cada 100 menores de 15 años. El cuarto y último grupo (integrado por tres países) se encuentra en la etapa

2 La Organización Mundial de la Salud (OMS) define a las personas mayores como todas las personas de 60 años o más en los países en desarrollo y de 65 años o más en los países desarrollados, teniendo en cuenta, entre otros factores, la esperanza de vida al nacer. No obstante, cada país es libre de establecer la edad en que su población se considera adulta mayor (en Costa Rica y el Uruguay, por ejemplo, una persona empieza a considerarse adulto mayor a partir de los 65 años). 
de envejecimiento avanzada, con menores niveles de fecundidad (por debajo de la tasa de reemplazo) e índices de envejecimiento por encima de 65 (CEPAL, 2007).

Cuadro 1

América Latina y el Caribe: etapas del proceso de envejecimiento de la población

\begin{tabular}{lll}
\hline Etapa & Descripción & Países \\
\hline $\begin{array}{l}\text { Envejecimiento } \\
\text { incipiente }\end{array}$ & $\begin{array}{l}\text { Países con niveles relativamente altos de } \\
\text { fecundidad (más de 3,3 hijos por mujer) y un } \\
\text { índice de envejecimiento de menos de 17 personas } \\
\text { mayores por cada 100 menores de 15 años }\end{array}$ & $\begin{array}{l}\text { Belice, Bolivia (Estado Plurinacional de), Guatemala, } \\
\text { Haití, Honduras, Nicaragua, Paraguay }\end{array}$ \\
\hline $\begin{array}{l}\text { Envejecimiento } \\
\text { moderado }\end{array}$ & $\begin{array}{l}\text { Países con tasas de fecundidad más bajas } \\
\text { (entre 2,3 y 3 hijos por mujer) e índices de } \\
\text { envejecimiento que oscilan entre 19,8 y 31,9 }\end{array}$ & $\begin{array}{l}\text { Bahamas, Brasil, Colombia, Costa Rica, Ecuador, } \\
\text { El Salvador, Guyana, Jamaica, México, Panamá, } \\
\text { Perú, República Dominicana, Santa Lucía, } \\
\text { Suriname, Venezuela (República Bolivariana de) }\end{array}$ \\
\hline $\begin{array}{l}\text { Envejecimiento } \\
\text { moderado a avanzado }\end{array}$ & $\begin{array}{l}\text { Países con tasas de fecundidad que varían } \\
\text { entre 1,7 y 2,5 hijos por mujer e índices de } \\
\text { envejecimiento que oscilan entre 32,8 y 51 personas } \\
\text { mayores por cada 100 menores de 15 años }\end{array}$ & Argentina, Chile, Trinidad y Tabago \\
\hline $\begin{array}{l}\text { Envejecimiento } \\
\text { avanzado }\end{array}$ & $\begin{array}{l}\text { Países con menores niveles de fecundidad } \\
\text { (por debajo de la tasa de reemplazo) e índices } \\
\text { de envejecimiento por encima de 65 }\end{array}$ & Barbados, Cuba, Uruguay \\
\hline
\end{tabular}

Fuente: Comisión Económica para América Latina y el Caribe (CEPAL), Informe sobre la aplicación de la Estrategia regional de implementación para América Latina y el Caribe del Plan de Acción Internacional de Madrid sobre el Envejecimiento (LC/L.2749(CRE-2/3)), Santiago, 2007.

A pesar de que el proceso de envejecimiento no ha tenido la misma intensidad, la tendencia pronto afectará a todos los países de la región. El aumento de la población adulta mayor se traducirá en incrementos proporcionales en las demandas sociales, económicas, políticas y culturales específicas de esta población. Esto debe abordarse y resolverse mediante políticas públicas que garanticen la inclusión social de estas personas, así como su calidad de vida y la protección y promoción de sus derechos (CEPAL, 2016a; Huenchuan, 2013). Al procurar garantizar una mayor autonomía e integración social de las personas mayores, los encargados de la formulación de políticas recurren cada vez más a la creación y puesta en marcha de iniciativas de inclusión digital para personas de edad, con el fin de capacitarlas en el uso y la apropiación de las tecnologías de la información y las comunicaciones (TIC) para sus actividades cotidianas.

Es bien sabido que los cambios relacionados con el auge de la sociedad digital y de la información han transformado profundamente la manera en que los habitantes de la región interactúan entre sí y con sus Gobiernos. Como señala la CEPAL (2016a), entre 2003 y 2015 - un período que abarca poco más de una década-, el número de usuarios de Internet se incrementó más del doble hasta representar el 54,4\% de la población. Como reflejo de las tendencias mundiales, la penetración de Internet (medida como el porcentaje del total de la población que tiene acceso a Internet) también se duplicó con creces en América Latina y el Caribe: pasó del 20,7\% en 2006 al 54,4\% en 2015. La última cifra, no obstante, se mantuvo muy por debajo del promedio del 79,6\% registrado por los países de la Organización de Cooperación y Desarrollo Económicos (OCDE).

La difusión de las TIC puede tener varias consecuencias, no solo en el ámbito económico sino también en el plano social y político. En este sentido, en la Cumbre Mundial sobre la Sociedad de la Información (CMSI) se ha buscado lograr una visión, un deseo y un compromiso común para construir una sociedad de la información centrada en las personas, inclusiva y orientada al desarrollo, en la que todos puedan crear, consultar, utilizar y compartir información (CMSI, 2016). Desde la primera Cumbre, celebrada en Ginebra en 2003, las TIC se han destacado como un instrumento clave para el desarrollo, con efectos directos en la educación, la salud y los servicios públicos, así como en el fortalecimiento de la democracia, la reducción de la pobreza y el fomento de la innovación y el crecimiento económico (Balboni, Rovira y Vergara, 2011). 
Cada vez resulta más evidente, sin embargo, que el acceso a los medios digitales no es uniforme entre los países y dentro de cada uno, lo que lleva a concluir que los posibles beneficios no se distribuyen por igual entre los distintos grupos de población. De hecho, los posibles efectos de los medios no son automáticos ni llegan a todas las personas. Al igual que otras diferencias económicas y sociales, este acceso desigual puede agravarse ante la falta de políticas adecuadas para garantizar el acceso digital y los beneficios a todos los sectores de la sociedad (Balboni, Rovira y Vergara, 2011). Sobre la base de esta perspectiva, en el presente artículo se argumenta que las TIC no solo tienen un gran potencial para reducir las desigualdades sociales y económicas que afectan a las personas de edad, sino que también pueden exacerbar las desigualdades económicas o sociales preexistentes, e incluso crear otras nuevas. En relación con el tema que se está examinando, las políticas públicas deben promover el papel positivo de las nuevas tecnologías como lo que son: instrumentos que pueden crear oportunidades para fomentar la inclusión de las personas mayores en todos los ámbitos de la vida cotidiana. La inclusión digital se considera, entonces, una manera de promover la inclusión social (Andreasson, 2015).

En este artículo se pone de relieve la importancia de integrar a las personas mayores al mundo digital, entre otras cosas porque en los próximos años ellos representarán un gran porcentaje de la población. El principal objetivo es analizar el uso de los medios digitales -especialmente Internetpor parte de las personas mayores en la región y reflexionar sobre la manera en que esos medios pueden contribuir a lograr una mayor inclusión y una mejor calidad de vida para esta población. Lo que se busca es saber si $-\mathrm{y}$ en qué medida - las personas mayores están aprovechando estas oportunidades. Con este fin, se intentará responder a las siguientes preguntas:

¿Cuáles son las modalidades de uso de las TIC entre las personas mayores? ¿Estas modalidades han ido cambiando con el tiempo? ¿Qué características individuales se relacionan con el uso de las TIC en la población adulta mayor?

Para responder a estas preguntas, el presente artículo se basa en datos de las encuestas de hogares de ocho países de la región: Chile, Ecuador, El Salvador, Honduras, México, Paraguay, Perú y Uruguay ${ }^{3}$. Los países considerados son los que recientemente han llevado a cabo encuestas de hogares que incluyen un módulo sobre las $\mathrm{TIC}^{4}$. En todos los casos, las encuestas son representativas a nivel nacional. Los países con dos rondas recientes que incluyen módulos sobre el uso de las TIC se utilizan para analizar los cambios en el uso de estas tecnologías por parte de las personas mayores. Las variables pertinentes se normalizaron a fin de efectuar comparaciones entre las encuestas ${ }^{5}$. La estrategia analítica incluyó análisis multivariables de regresión logística para identificar las características individuales relacionadas con el uso de las TIC entre las personas mayores en la región.

El presente artículo se divide en seis secciones, incluida esta introducción. En la sección II se compara el acceso a Internet entre las personas mayores y otros grupos de edad, y se examina el concepto de brecha digital relacionada con la edad. En la sección III se describen las modalidades y

3 Estas encuestas son: la Encuesta de Caracterización Socioeconómica Nacional (CASEN) de Chile, 2015; la Encuesta de Empleo, Desempleo y Subempleo en el área urbana y rural del Ecuador, 2015; la Encuesta de Hogares de Propósitos Múltiples de El Salvador, 2015; la Encuesta Permanente de Hogares de Propósitos Múltiples de Honduras, 2014; el Módulo sobre Disponibilidad y Uso de Tecnologías de la Información en los Hogares (MODUTIH) de México, 2014; la Encuesta Permanente de Hogares del Paraguay, 2015; la Encuesta Nacional de Hogares sobre Condiciones de Vida y Pobreza del Perú, 2015, y la Encuesta Continua de Hogares del Uruguay, 2015.

4 La mayoría de las encuestas de hogares de los países de la región incluyen información sobre la disponibilidad de TIC a nivel de los hogares: si el hogar tiene un teléfono móvil, una computadora y una conexión a Internet. Las ocho encuestas utilizadas en este análisis incluyen información sobre el uso de las TIC a nivel individual, que se considera superior a la información a nivel del hogar, ya que el acceso general del hogar a las TIC no garantiza que estas tecnologías sean utilizadas por todos sus integrantes. Los módulos de las TIC a nivel individual contienen preguntas sobre el uso de teléfonos móviles, computadoras e Internet por parte de cada miembro del hogar, así como la frecuencia y el lugar de uso. Dado el creciente interés en el uso de las TIC entre los habitantes en la región, se han elaborado e incorporado módulos normalizados, lo que facilita las comparaciones entre las distintas encuestas.

5 Véanse las características de la muestra en el anexo A1. 
tendencias de uso de las TIC por parte de las personas mayores en la región, utilizando datos de las encuestas nacionales de hogares de siete países. En la sección IV se identifican los determinantes de estos tipos de uso de Internet entre la población adulta mayor, teniendo en cuenta variables tales como el sexo, el origen étnico (pertenencia a un grupo indígena), el nivel educativo y la residencia rural o urbana. En la sección $\vee$ se detallan las políticas y los programas que se están aplicando para promover la inclusión de las personas mayores mediante el uso de las TIC. Por último, en la sección $\mathrm{VI}$ se presentan las conclusiones y se formulan algunas recomendaciones para promover el uso de estas tecnologías entre la población adulta mayor.

\section{La brecha de la era digital}

Históricamente, las personas mayores han sido consideradas personas con una capacidad disminuida para llevar a cabo actividades productivas relacionadas con el proceso económico. La tendencia a subestimar la experiencia y los conocimientos de las personas de edad ha llevado a que se las considere sujetos pasivos en el proceso de desarrollo de las sociedades (Abusleme y otros, 2014) y, por lo tanto, al margen del progreso social.

En la actualidad, las políticas públicas procuran modificar esta idea de las personas de edad mediante campañas que promueven la cultura del "envejecimiento activo", definido como el proceso de optimización de las oportunidades de salud, participación y seguridad, con el fin de mejorar la calidad de vida a medida que las personas envejecen. Esto se aplica tanto a las personas como a los grupos de población, y permite a los individuos desarrollar su potencial de bienestar físico, social y mental durante toda la vida y participar en la sociedad, al tiempo que les proporciona un nivel adecuado de protección, seguridad y atención cuando precisan asistencia (OMS, 2002). No hay duda de que la promoción del acceso y uso de medios digitales entre las personas mayores es esencial para alentar la cultura del envejecimiento activo.

Sin embargo, uno de los efectos sociales de las tecnologías digitales en el mundo moderno es que se han convertido en un factor "nuevo", que distingue a las personas mayores de los grupos de población más jóvenes. De hecho, las estadísticas de TIC disponibles para América Latina muestran que el grupo etario de personas mayores es el más aislado de las tecnologías digitales, lo que da cuenta de una profunda brecha de la era digital.

El de brecha digital es un concepto dicotómico que se utilizó por primera vez en los años noventa para hacer referencia a la brecha que se estaba creando entre los países, los grupos sociales y las personas que tenían acceso a las tecnologías digitales y los que no lo tenían (Selwyn, 2004; Selwyn y Facer, 2007). El concepto es particularmente pertinente cuando se refiere a la realidad de los países en desarrollo con una población en proceso de envejecimiento y donde las tecnologías digitales pueden tener un profundo impacto en la vida de las personas mayores.

Prensky (2001) se refirió a la importancia de distinguir entre los nativos digitales y los inmigrantes digitales. El autor señala que los primeros - niños y jóvenes que nacieron y crecieron en la era digitalse caracterizan por una continua y prolongada exposición a los medios digitales y por el grado en que los integran (naturalmente) a sus actividades cotidianas. Los inmigrantes digitales, en cambio, son aquellos que no nacieron en el mundo digital y han tenido que adaptarse al nuevo entorno (Prensky, 2001). Esta categoría incluye a las personas mayores que vienen de un "entorno" cultural distinto y han tenido que lidiar con las innovaciones tecnológicas para tratar de incluirlas en su vida diaria (Piscitelli, 2009).

Hay numerosas pruebas de que en América Latina existe una brecha digital entre las personas de 60 años y más y otros grupos etarios de la población. En el gráfico 2 se muestra que las personas 
de edad usan menos Internet que los jóvenes y las personas en todos los países para los que se dispone de datos y las brechas son bastante sorprendentes. Se informó, por ejemplo, que el uso de Internet entre las personas de 15 a 29 años era más de siete veces superior al de las personas mayores en El Salvador y Honduras, ocho veces superior en México y casi nueve veces superior en el Ecuador6.

Gráfico 2

América Latina (países seleccionados): personas que usan Internet, por grupo etario, alrededor de $2015^{a}$

(En porcentajes)

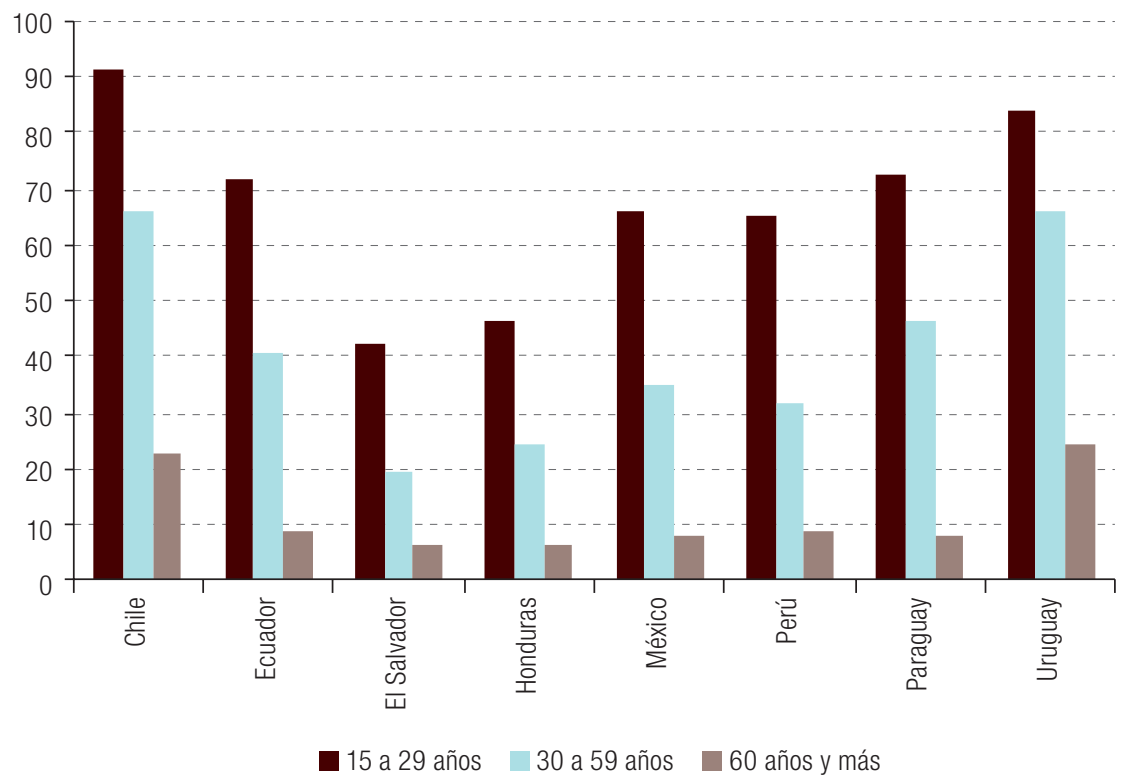

Fuente: Chile: Encuesta de Caracterización Socioeconómica Nacional (CASEN), 2015; Ecuador: Encuesta Nacional de Empleo, Desempleo y Subempleo en el área urbana y rural, 2015; El Salvador: Encuesta de Hogares de Propósitos Múltiples, 2015; Honduras: Encuesta Permanente de Hogares de Propósitos Múltiples, 2014; México: Módulo sobre Disponibilidad y Uso de Tecnologías de la Información en los Hogares (MODUTIH), 2014; Paraguay: Encuesta Permanente de Hogares, 2015; Perú: Encuesta Nacional de Hogares sobre Condiciones de Vida y Pobreza, 2015; Uruguay: Encuesta Continua de Hogares, 2015.

a Las encuestas se realizaron en 2015, salvo en Honduras y México, donde se llevaron a cabo en 2014.

Las modalidades de uso y los lugares de acceso también difieren entre los distintos subgrupos de población. En el cuadro 2 se muestran los lugares más comunes de acceso a Internet entre los grupos etarios de 15 a 29 años, de 30 a 59 años y de 60 años y más en seis países. Se observan diferencias claras entre los distintos grupos de edad. Lo más destacado es que a medida que aumenta la edad, también aumenta el porcentaje de usuarios que acceden a Internet en el hogar, mientras que porcentajes más elevados de jóvenes acceden desde lugares públicos y escuelas $u$ otros establecimientos educativos.

\footnotetext{
6 Si se hubieran desglosado los datos de las personas mayores en dos grupos (de 60 a 74 años y de más de 75 años), se habrían visto más diferencias en el uso de Internet, pero esto no fue posible debido a las limitaciones de tamaño de la muestra.
} 


\section{Cuadro 2}

América Latina (países seleccionados):

uso de Internet, por lugar de acceso y grupo etario, alrededor de $2015^{\mathrm{a}}$

(En porcentajes)

\begin{tabular}{|c|c|c|c|c|c|}
\hline País & Edad & Hogar & Lugar de trabajo & Escuela & Lugar público \\
\hline \multirow{3}{*}{ Chile } & $15-29$ & 76,6 & 6,1 & 6,8 & 0,3 \\
\hline & $30-59$ & 77,0 & 15,3 & 0,1 & 0,2 \\
\hline & 60 y más & 86,6 & 9,5 & 0,0 & 0,2 \\
\hline \multirow{3}{*}{ Ecuador } & $15-29$ & 52,8 & 12,5 & 23,7 & 48,1 \\
\hline & $30-59$ & 73,4 & 34,8 & 2,5 & 23,0 \\
\hline & 60 y más & 89,0 & 27,7 & 1,6 & 8,4 \\
\hline \multirow{3}{*}{ El Salvador } & $15-29$ & 33,5 & 2,2 & 5,7 & 0,1 \\
\hline & $30-59$ & 53,8 & 10,0 & 0,3 & 0,0 \\
\hline & 60 y más & 83,7 & 5,5 & 0,4 & 0,0 \\
\hline \multirow{3}{*}{ Honduras } & $15-29$ & 33,1 & 8,6 & 16,4 & \\
\hline & $30-59$ & 43,8 & 25,7 & 2,6 & \\
\hline & 60 y más & 67,4 & 15,2 & 0,6 & \\
\hline \multirow{3}{*}{ México } & $15-29$ & 48,9 & 8,1 & 7,9 & 31,5 \\
\hline & $30-59$ & 63,0 & 20,3 & 0,0 & 13,3 \\
\hline & 60 y más & 79,5 & 12,5 & 0,3 & 5,5 \\
\hline \multirow{3}{*}{ Perú } & $15-29$ & 33,7 & 9,1 & 8,5 & \\
\hline & $30-59$ & 53,1 & 27,3 & 0,9 & \\
\hline & 60 y más & 75,4 & 23,6 & 0,7 & \\
\hline
\end{tabular}

Fuente: Chile: Encuesta de Caracterización Socioeconómica Nacional (CASEN), 2015; Ecuador: Encuesta Nacional de Empleo, Desempleo y Subempleo en el área urbana y rural, 2015; El Salvador: Encuesta de Hogares de Propósitos Múltiples, 2015; Honduras: Encuesta Permanente de Hogares de Propósitos Múltiples, 2015; México: Módulo sobre Disponibilidad y Uso de Tecnologías de la Información en los Hogares (MODUTIH), 2014; Perú: Encuesta Nacional de Hogares sobre Condiciones de Vida y Pobreza, 2015.

a Las encuestas se realizaron en 2015, salvo en México, donde se llevó a cabo en 2014.

Los resultados del análisis de la brecha digital en la región indican que las personas mayores utilizan Internet menos que otros grupos etarios de la población, pero son los que más acceden desde el hogar. Esta tendencia puede atribuirse a limitaciones de movilidad o problemas de salud que limitan su capacidad para salir de casa. También hay algunas personas mayores que pueden decidir no salir de casa. En oposición, las cifras indican que los más jóvenes dependen principalmente del acceso a Internet fuera del hogar. Si bien los datos no permitieron realizar una medición directa del acceso a Internet a través de dispositivos móviles fuera del hogar, es posible que una proporción incluso mayor de jóvenes acceda de esta manera.

\section{Modalidades de uso de las TIC por parte de las personas mayores en América Latina}

Lo que se pretende con este artículo es saber si -y en qué medida- las personas mayores están aprovechando las oportunidades que traen aparejadas las TIC. Con este fin, se consideran las modalidades de uso de estas tecnologías entre las personas mayores y si estas modalidades han ido cambiando con el tiempo, así como las características individuales relacionadas con el uso de las TIC entre la población adulta mayor. El objetivo es proporcionar un amplio panorama estadístico de la utilización de las tecnologías por parte de las personas de edad y, de ese modo, ofrecer pruebas y recomendaciones que puedan ayudar a formular políticas que mejor incorporen a las personas mayores a la sociedad digital. 
Los datos sobre el acceso de las personas mayores a una computadora muestran variaciones sustanciales entre los países estudiados (véase el gráfico 3). Mientras que el 45,7\% de las personas mayores del Uruguay tienen una computadora en su hogar, este número se reduce al $16,6 \%$ en Honduras. Esta diversidad no es sorprendente, habida cuenta de las considerables brechas en materia de desarrollo económico y social en la región. Lo que también se desprende claramente del gráfico 3 es que el acceso del hogar a una computadora no equivale a la utilización de dicha herramienta por parte de las personas mayores. En cinco de los siete países para los que se dispone de ambos indicadores (Ecuador, El Salvador, México, Paraguay y Perú), el porcentaje de esta población que usa computadoras es inferior a la proporción que tiene una computadora en su hogar. Esto supone que hay un segmento de la población adulta mayor que en teoría tiene acceso a una computadora, pero no la usa.

\section{Gráfico 3}

América Latina (países seleccionados): personas de 60 años o más que tienen computadora en su hogar y usan computadora, alrededor de $2015^{\mathrm{a}}$

(En porcentajes)

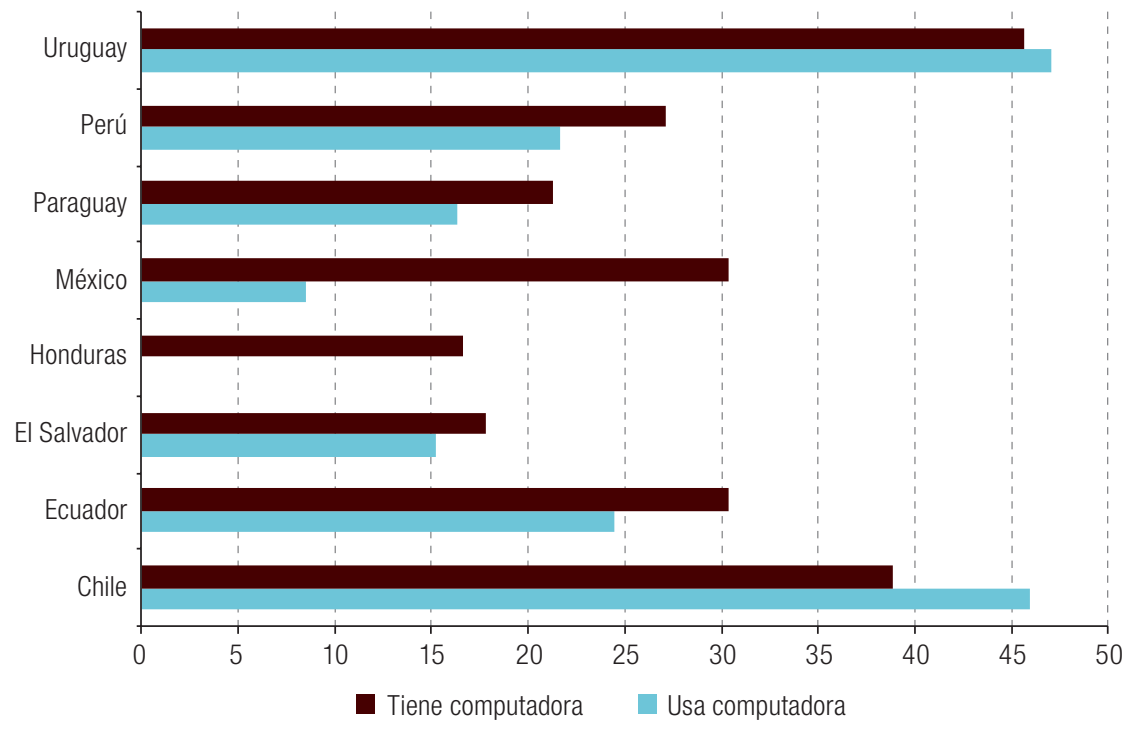

Fuente: Chile: Encuesta de Caracterización Socioeconómica Nacional (CASEN), 2015; Ecuador: Encuesta Nacional de Empleo, Desempleo y Subempleo en el área urbana y rural, 2015; El Salvador: Encuesta de Hogares de Propósitos Múltiples, 2015; Honduras: Encuesta Permanente de Hogares de Propósitos Múltiples, 2015; México: Módulo sobre Disponibilidad y Uso de Tecnologías de la Información en los Hogares (MODUTIH), 2014; Paraguay: Encuesta Permanente de Hogares, 2015; Perú: Encuesta Nacional de Hogares sobre Condiciones de Vida y Pobreza, 2015; Uruguay: Encuesta Continua de Hogares, 2015.

a Las encuestas se realizaron en 2015, salvo en México, donde se llevó a cabo en 2014.

En relación con lo expuesto anteriormente, el porcentaje de personas mayores que utilizan Internet también es bajo y va del 24,5\% en el Uruguay al 6,1\% en Honduras (véase el gráfico 4). Esta variación no solo refleja la desigualdad en los niveles educativos de la población en cada uno de los países, sino también, de manera más general, en los niveles de desarrollo económico y social, así como en la disponibilidad de banda ancha y conexión a Internet. 


\section{Gráfico 4}

América Latina (países seleccionados):

personas de 60 años o más que usan Internet, alrededor de 2015ª

(En porcentajes)

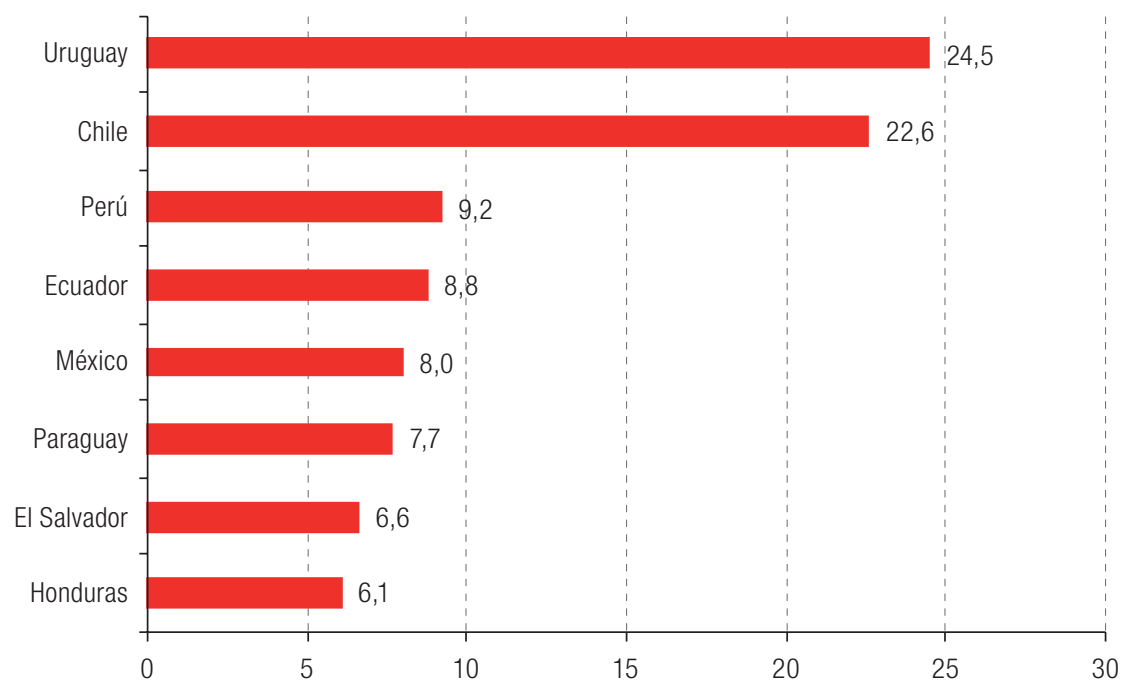

Fuente: Chile: Encuesta de Caracterización Socioeconómica Nacional (CASEN), 2015; Ecuador: Encuesta Nacional de Empleo, Desempleo y Subempleo en el área urbana y rural, 2015; El Salvador: Encuesta de Hogares de Propósitos Múltiples, 2015; Honduras: Encuesta Permanente de Hogares de Propósitos Múltiples, 2014; México: Módulo sobre Disponibilidad y Uso de Tecnologías de la Información en los Hogares (MODUTIH), 2014; Paraguay: Encuesta Permanente de Hogares, 2015; Perú: Encuesta Nacional de Hogares sobre Condiciones de Vida y Pobreza, 2015; Uruguay: Encuesta Continua de Hogares, 2015.

a Las encuestas se realizaron en 2015, salvo en México, donde se llevó a cabo en 2014.

Los datos indican que las personas mayores no son participantes activos en las sociedades digitales en las que viven y que existe un enorme espacio para ampliar el uso de Internet entre estas personas en la región. Selwyn (2003) sostiene que el acceso a los medios digitales y su utilización dependen de las características particulares de cada persona. El autor examina diversos factores que pueden influir en la decisión de quienes no son usuarios (o "no están en línea") de no utilizar medios digitales. Estos factores incluyen: discursos de deficiencia material y cognitiva, tecnofobia, rechazo ideológico y teoría de la difusión.

Con respecto al primer factor, Selwyn plantea que los discursos de restricciones materiales se relacionan con recursos económicos y materiales. Para algunas personas - sobre todo las que se encuentran en condiciones menos favorables - , el costo de un dispositivo digital podría determinar la calidad del dispositivo adquirido, o incluso si se adquiere un dispositivo. Sin embargo, el acceso a medios digitales es irrelevante si hay limitaciones en cuanto a su uso. El autor afirma que los discursos de deficiencia cognitiva están relacionados con la capacidad intelectual y los conocimientos tecnológicos, y que las actitudes hacia las nuevas tecnologías se tornan más positivas a medida que las personas van adquiriendo más experiencia en su utilización (Selwyn, 2003).

Respecto del segundo factor - la tecnofobia, entendida como el miedo (y la aprehensión) de una persona a la tecnología, en particular a las consecuencias de su uso-, Selwyn observa una correlación significativa con ciertas características individuales, tales como el género y la edad. El sentimiento de ansiedad que habitualmente produce la tecnofobia, no obstante, puede desaparecer en la medida en que aumente la interacción con la tecnología. A este respecto, Van Deursen y Van Dijk (2014) señalan que las características personales pueden incidir en la motivación, el acceso, los conocimientos y el uso de los medios digitales. Es por ello que quienes se dedican al desarrollo de tecnología tratan de crear tecnologías fáciles de usar, es decir, equipos y programas informáticos 
especialmente diseñados para facilitar su uso. El tercer factor -el rechazo ideológico - refleja una opción individual de las personas que, aun cuando estén en condiciones de hacerlo, no desean relacionarse con la tecnología. Por último, Selwyn (2003) sostiene que la teoría de la difusión puede explicar la reticencia de quienes no la utilizan a comprar y adoptar una tecnología que pronto será reemplazada por otra más nueva en el mercado.

Siguiendo esta línea de pensamiento, Castaño (2008) afirma que, si bien la brecha digital puede parecer de carácter tecnológico, es más bien de tipo social. Esto se debe a que la brecha digital - entendida como la desigualdad en el acceso y uso de Internet entre las generaciones (Boonaert y Vettenburg (2011) citado en Elwick y otros, 2013) - se interrelaciona con otros factores que inciden en la exclusión social (como los recursos económicos, la disponibilidad de tiempo, los conocimientos, las aptitudes y el bagaje cultural y lingüístico). La brecha digital puede explicarse por los distintos intereses, necesidades, experiencias, actitudes y valores de cada grupo de edad. La percepción respecto de la utilidad de una tecnología para determinada actividad condicionará el grado de interacción de una persona con dicha tecnología e incluso su reticencia a utilizarla. En este sentido, el grado de uso de Internet dependerá de cómo, por quién y por qué se utiliza (Camacho, 2004).

En consonancia con el modelo de Murdock, citado en Selwyn (2003), y sobre la base de los datos disponibles, los jóvenes y los adultos pueden clasificarse en general como "usuarios principales", mientras que las personas de edad pueden catalogarse como "usuarios periféricos" o "usuarios excluidos" de Internet a los efectos de la búsqueda de información, la comunicación y la producción de materiales (véase el cuadro 3).

Cuadro 3

Tipos de usuarios de las tecnologías de la información y las comunicaciones (TIC)

\begin{tabular}{ll}
\hline Usuarios "principales" & $\begin{array}{l}\text { Uso continuo y amplio de las TIC para búsqueda de información, } \\
\text { comunicación y creación o producción de materiales }\end{array}$ \\
\hline Usuarios "periféricos" & $\begin{array}{l}\text { Uso esporádico y limitado de las TIC para búsqueda de información, } \\
\text { comunicación y creación o producción de materiales }\end{array}$ \\
\hline Usuarios "excluidos" & $\begin{array}{l}\text { Uso inexistente de las TIC para búsqueda de información, } \\
\text { comunicación y creación o producción de materiales }\end{array}$ \\
\hline
\end{tabular}

Fuente: N. Selwyn, "Apart from technology: understanding people's non-use of information and communication technologies in everyday life", Technology in Society, vol. 25, № 1, Amsterdam, Elsevier, 2003.

Los distintos grados de interacción con las TIC se relacionan con lo que se dio en llamar la "segunda brecha digital" (Castaño, 2008, pág. 24), que afecta el tipo de uso (en términos de intensidad y variedad) y está determinada por el acceso de las personas a una computadora y a Internet, y sus aptitudes para usar estas herramientas. Van Deursen y Van Dijk (2014) sostienen que las competencias digitales son fundamentales para todo el proceso de apropiación de estas nuevas tecnologías y que para desarrollar esas competencias se necesita motivación y un esfuerzo constante.

\section{Evolución del uso de las TIC entre las personas mayores}

Pese al bajo nivel de acceso a computadoras y de uso de Internet que en general tienen las personas mayores en la región, mencionado anteriormente, cabe señalar que en los últimos cinco años se ha registrado un importante aumento en el uso de las TIC en esta población, en un contexto más amplio de penetración de Internet y las TIC en la región (CEPAL, 2016b). En lo que respecta al acceso a una computadora en el hogar (véase el gráfico 5), el aumento fue mayor en el Uruguay, donde el porcentaje de personas de edad que vivían en un hogar con computadora aumentó de poco menos del 19\% en 2008 a más del 45\% en 2015 (la proporción se duplicó con creces en solo siete años). 


\section{Gráfico 5}

América Latina (países seleccionados):

personas de 60 años o más que viven en hogares con computadora, 2008 y 2015

(En porcentajes)

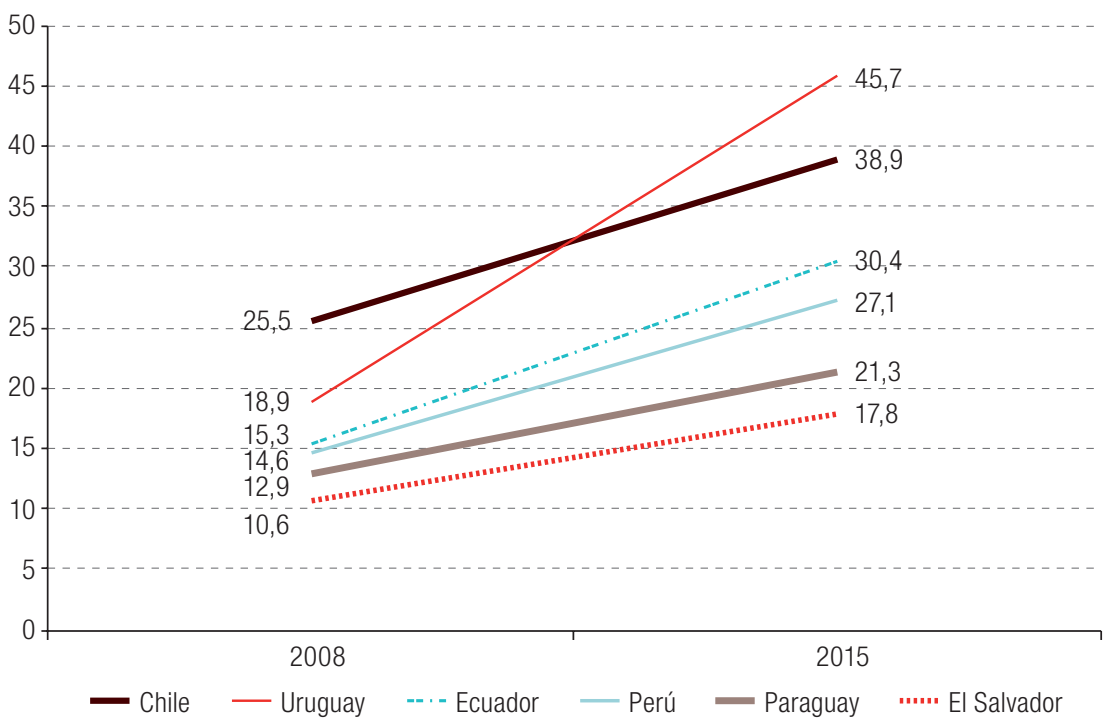

Fuente: Chile: Encuesta de Caracterización Socioeconómica Nacional (CASEN), 2015 y 2009; Ecuador: Encuesta Nacional de Empleo, Desempleo y Subempleo en el área urbana y rural, 2015 y 2008; El Salvador: Encuesta de Hogares de Propósitos Múltiples, 2015 y 2008; Paraguay: Encuesta Permanente de Hogares, 2015 y 2008; Perú: Encuesta Nacional de Hogares sobre Condiciones de Vida y Pobreza, 2015 y 2008; Uruguay: Encuesta Continua de Hogares, 2015 y 2008.

Los datos muestran aumentos correlativos en el uso de Internet por parte de las personas mayores (véase el gráfico 6), aunque estos niveles aún son bastante bajos en algunos países: menos del $10 \%$ de las personas mayores en tres de los cinco países examinados respondieron que utilizan Internet.

\section{Gráfico 6}

América Latina (países seleccionados): personas de 60 años o más que usan Internet, 2008 y 2015

(En porcentajes)

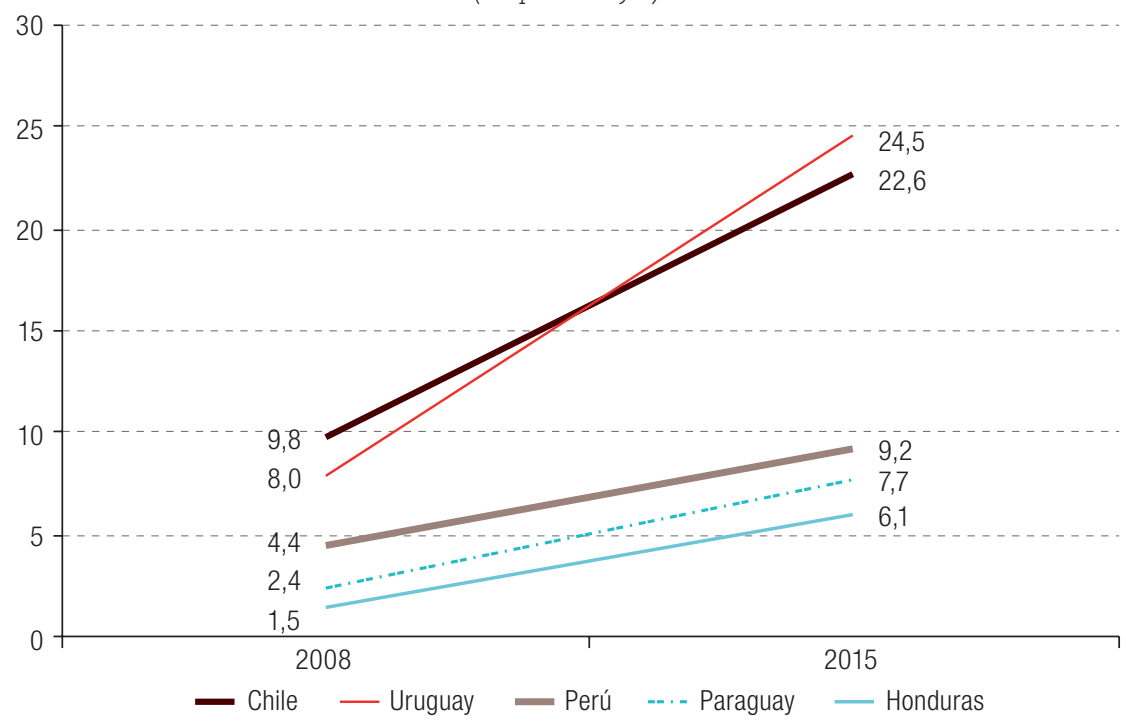

Fuente: Chile: Encuesta de Caracterización Socioeconómica Nacional (CASEN), 2015 y 2009; Honduras: Encuesta Permanente de Hogares de Propósitos Múltiples, 2015 y 2008; Paraguay: Encuesta Permanente de Hogares, 2015 y 2008; Perú: Encuesta Nacional de Hogares sobre Condiciones de Vida y Pobreza, 2015 y 2008; Uruguay: Encuesta Continua de Hogares, 2015 y 2008. 


\section{Características del uso de Internet por parte de las personas mayores}

Aunque, en general, solo un pequeño porcentaje de las personas de edad en América Latina utilizan Internet, quienes lo hacen son usuarios frecuentes y la mayoría se conecta todos los días (véase el gráfico 7). Esto indica que Internet se ha vuelto algo cotidiano para las personas mayores que la han adoptado. El alto nivel de acceso y uso de Internet en un segmento de la población adulta mayor en América Latina indica que son "usuarios principales", según la clasificación del cuadro 3. Sin embargo, estos datos no muestran cuánto del uso que hacen de Internet se dedica a búsqueda de información, comunicación o producción de contenido.

Gráfico 7

América Latina (países seleccionados): frecuencia de uso de Internet por parte de las personas de 60 años o más, alrededor de $2015^{a}$

(En porcentajes)

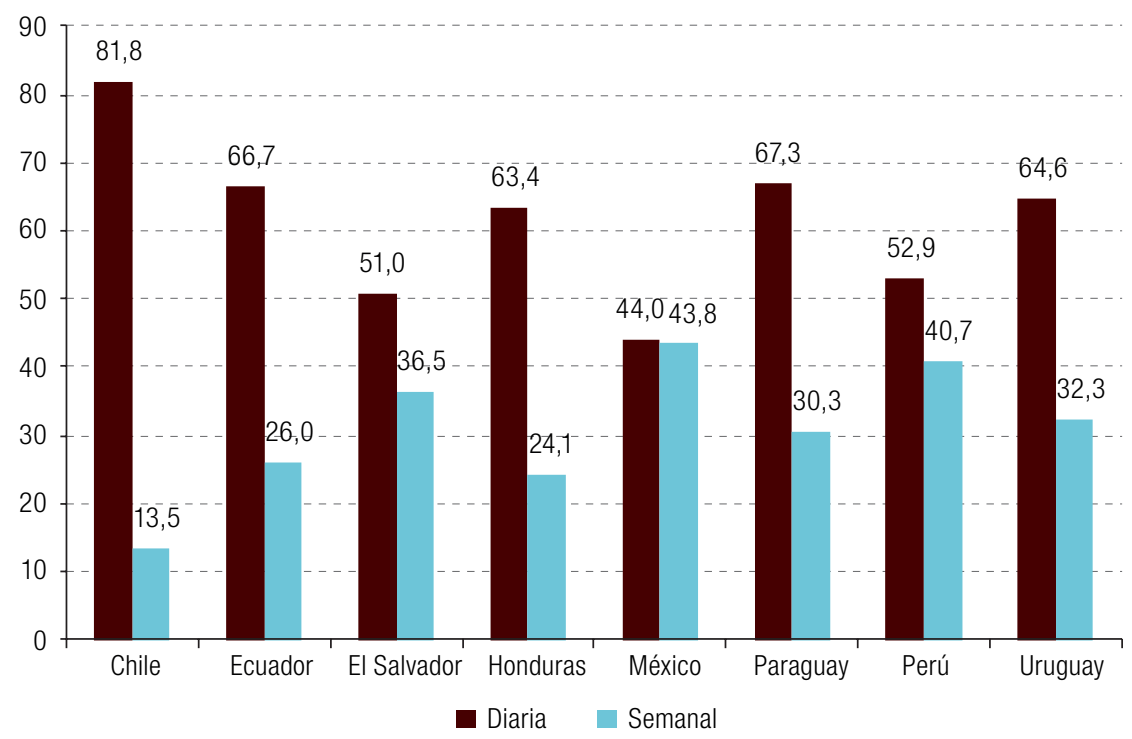

Fuente: Chile: Encuesta de Caracterización Socioeconómica Nacional (CASEN), 2015; Ecuador: Encuesta Nacional de Empleo, Desempleo y Subempleo en el área urbana y rural, 2015; El Salvador: Encuesta de Hogares de Propósitos Múltiples, 2015; Honduras: Encuesta Permanente de Hogares de Propósitos Múltiples, 2015; México: Módulo sobre Disponibilidad y Uso de Tecnologías de la Información en los Hogares (MODUTIH), 2014; Paraguay: Encuesta Permanente de Hogares, 2015; Perú: Encuesta Nacional de Hogares sobre Condiciones de Vida y Pobreza, 2015; Uruguay: Encuesta Continua de Hogares, 2015.

a Las encuestas se realizaron en 2015, salvo en México, donde se llevó a cabo en 2014.

A fin de determinar las principales actividades que realizan en línea las personas mayores de la región, en este artículo se examinan las actividades incluidas en las encuestas de hogares: búsqueda de información, comunicación (incluidos el correo electrónico y el chat), educación (y capacitación), entretenimiento, operaciones bancarias electrónicas, compras y tareas administrativas. Pese a la heterogeneidad antes mencionada en relación con el uso que las personas mayores hacen de Internet en los países objeto de análisis, los tipos de actividades son, en cierto modo, uniformes en los distintos países. Internet se utiliza principalmente para la búsqueda de información y la comunicación (véase el gráfico 8). 


\section{Gráfico 8}

América Latina (países seleccionados): personas de 60 años o más que usan Internet, por tipo de actividad, alrededor de 2015

(En porcentajes)

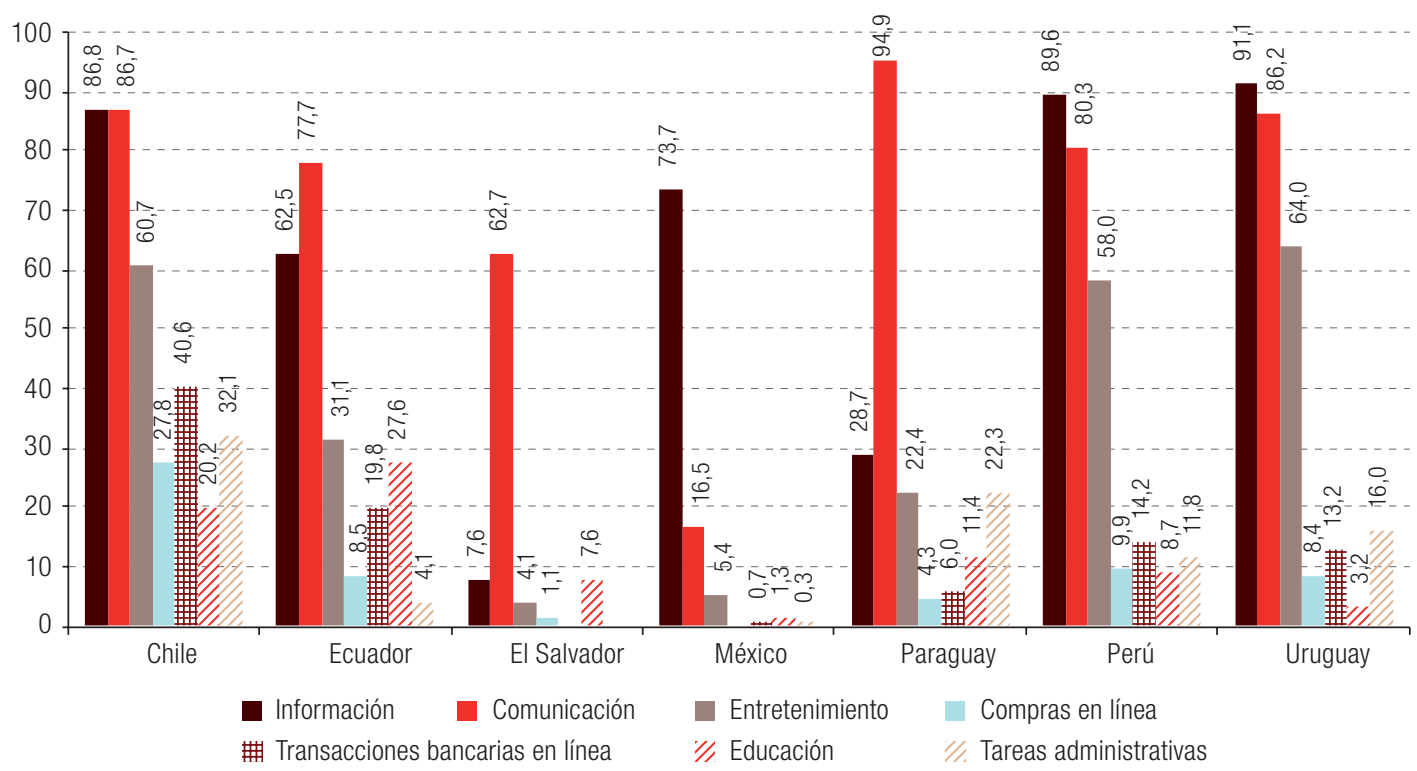

Fuente: Chile: Encuesta de Caracterización Socioeconómica Nacional (CASEN), 2015; Ecuador: Encuesta Nacional de Empleo, Desempleo y Subempleo en el área urbana y rural, 2015; El Salvador: Encuesta de Hogares de Propósitos Múltiples, 2015; Honduras: Encuesta Permanente de Hogares de Propósitos Múltiples, 2014; México: Módulo sobre Disponibilidad y Uso de Tecnologías de la Información en los Hogares (MODUTIH), 2010; Paraguay: Encuesta Permanente de Hogares, 2015; Perú: Encuesta Nacional de Hogares sobre Condiciones de Vida y Pobreza, 2015; Uruguay: Encuesta Continua de Hogares, 2015.

Entre las personas mayores es especialmente importante el uso de Internet para la comunicación. Los programas de videotelefonía (como Skype o FaceTime) permiten realizar reuniones virtuales con personas en cualquier lugar y, junto con otras herramientas de comunicación, proporcionan una vía para que las personas mayores puedan mantenerse en contacto con sus familiares y amigos, en una época en que es frecuente que las familias vivan lejos. Además, las herramientas de comunicación en línea permiten a las personas mayores con problemas de movilidad o audición mantener vínculos sociales e interpersonales sin tener que salir de casa. Si bien cabría esperar que los problemas de movilidad o comunicación hicieran que otras actividades, tales como las compras o las transacciones bancarias por Internet, fueran más frecuentes entre las personas mayores, estas registraron niveles bajos en la mayoría de los países considerados.

El temor a utilizar la tecnología (debido a la percepción de que no se la sabe usar bien), así como las amenazas a la seguridad y la desconfianza asociada a la realización de transacciones financieras en dispositivos digitales, son factores que posiblemente contribuyan a que las personas mayores se muestren reticentes a utilizar la banca electrónica o a comprar en línea. En las sociedades latinoamericanas, además, las salidas al banco o a la tienda pueden representar oportunidades de interacción y socialización con otras personas, y, en ese sentido, pueden ser valoradas por las personas de edad, incluidas aquellas con limitaciones de movilidad o comunicación.

Los datos también indican que un elevado porcentaje de usuarios se conecta a Internet para realizar actividades de entretenimiento, como ver y descargar vídeos, música y películas. En Chile, el $60,7 \%$ de las personas mayores utilizan Internet para entretenimiento, mientras que esa cifra se sitúa en el $64 \%$ en el Uruguay. Los medios digitales no son un simple pasatiempo para las personas mayores, sino que también pueden servir para combatir la soledad. No obstante, las formas tradicionales de 
entretenimiento e interacción social siguen estando muy arraigadas entre las personas de edad en estas sociedades.

Por último, es interesante señalar que en países como Chile y el Uruguay, donde el uso de Internet está más extendido en general, las personas de edad parecen participar en un conjunto más amplio de actividades en línea, en particular para realizar procedimientos administrativos en instituciones públicas.

\section{Características del uso de Internet por parte de las personas mayores}

En la presente sección se utilizan modelos multivariables de regresión logística para identificar predictores de posesión de una computadora y uso de Internet. Esto pone de relieve los factores sociodemográficos relacionados con estos dos indicadores, lo que puede ayudar a determinar qué grupos sociales podrían beneficiarse de la adopción de medidas concretas para ampliar el acceso a las TIC.

A continuación, se presentan las razones de probabilidades de los análisis multivariables de regresión logística para identificar predictores de posesión de una computadora (véase el cuadro 4) y uso de Internet (véase el cuadro 5) entre las personas mayores de la región. Una razón de probabilidades de 1 significa que la variable no afecta el resultado (en este caso, uno de los dos indicadores del uso de las TIC). Los valores por debajo de 1 indican menos posibilidades de uso de las TIC, mientras que los valores mayores que 1 indican más posibilidades de uso de estas tecnologías.

\section{Cuadro 4}

América Latina (países seleccionados): razones de probabilidades de análisis multivariables de coeficientes de regresión logística que predicen la posesión de una computadora entre las personas de 60 años o más

\begin{tabular}{|c|c|c|c|c|c|c|c|}
\hline & Chile & Ecuador & El Salvador & México & Paraguay & Perú & Uruguay \\
\hline Edad media & $0,98^{\star *}$ & 1,00 & $1,01^{\wedge}$ & $1,01^{\star \star}$ & $1,01^{*}$ & $1,02^{\star \star}$ & $0,97^{\star \star}$ \\
\hline Hombre & $0,42^{\star *}$ & $0,83^{\star *}$ & $0,75^{\star \star}$ & $0,83^{\star \star}$ & 1,00 & $0,73^{\star *}$ & $1,12^{\star \star}$ \\
\hline Urbana & $1,30^{* *}$ & $2,95^{\star \star}$ & $2,88^{\star *}$ & $3,85^{\star *}$ & $4,43^{\star *}$ & $6,54^{\star *}$ & $1,64^{* *}$ \\
\hline Años de educación & $1,09^{* *}$ & $1,23^{\star *}$ & $1,18^{\star \star}$ & $1,23^{\star \star}$ & $1,21^{* *}$ & $1,19^{\star *}$ & $1,25^{\star *}$ \\
\hline Origen étnico indígena & $0,87^{\star *}$ & $0,71^{\star *}$ & 1,00 & $0,72^{\star \star}$ & 1,00 & $0,94 \wedge$ & 0,97 \\
\hline Con hijos & $2,00^{* *}$ & $5,95^{\star \star}$ & $3,17^{\star \star}$ & $3,56^{\star \star}$ & $5,27^{\star *}$ & $5,84^{\star *}$ & $5,95^{\star *}$ \\
\hline
\end{tabular}

Fuente: Chile: Encuesta de Caracterización Socioeconómica Nacional (CASEN), 2015; Ecuador: Encuesta Nacional de Empleo, Desempleo y Subempleo en el área urbana y rural, 2015; El Salvador: Encuesta de Hogares de Propósitos Múltiples, 2015; Honduras: Encuesta Permanente de Hogares de Propósitos Múltiples, 2015; México: Módulo sobre Disponibilidad y Uso de Tecnologías de la Información en los Hogares (MODUTIH), 2015; Paraguay: Encuesta Permanente de Hogares, 2015; Perú: Encuesta Nacional de Hogares sobre Condiciones de Vida y Pobreza, 2015; Uruguay: Encuesta Continua de Hogares, 2015.

Nota: Los resultados son estadísticamente significativos a nivel de ${ }^{\star *} 0,01,{ }^{\star} 0,05 \mathrm{y}^{\star \star \star} 0,10$. 


\section{Cuadro 5}

América Latina (países seleccionados): razones de probabilidades de análisis multivariables de coeficientes de regresión logística que predicen el uso de Internet entre las personas de 60 años o más

\begin{tabular}{|c|c|c|c|c|c|}
\hline & Chile & Ecuador & El Salvador & Perú & Uruguay \\
\hline Edad media & $0,93^{\star \star}$ & $0,91^{\star \star}$ & $0,96^{\star \star}$ & $0,92^{\star *}$ & $0,91^{\star *}$ \\
\hline Hombre & $1,10^{\star *}$ & $1,24^{* \star}$ & 1,09 & $1,32^{* *}$ & 1,00 \\
\hline Urbana & $2,31^{\star *}$ & $2,23^{\star *}$ & $2,58^{* *}$ & $5,09^{* *}$ & $1,62^{\star *}$ \\
\hline Promedio de años de educación & $1,36^{\star \star}$ & $1,44^{\star \star}$ & $1,40^{\star *}$ & $1,43^{\star *}$ & $1,37^{\star *}$ \\
\hline Origen étnico indígena & $0,80^{\star \star}$ & 0,95 & 1,00 & $0,74^{* *}$ & $0,81^{* *}$ \\
\hline Con hijos & $1,13^{\star \star}$ & $0,82^{*}$ & 0,93 & 0,99 & $0,81^{\star \star}$ \\
\hline
\end{tabular}

Fuente: Chile: Encuesta de Caracterización Socioeconómica Nacional (CASEN), 2015; Ecuador: Encuesta Nacional de Empleo, Desempleo y Subempleo en el área urbana y rural, 2010; El Salvador: Encuesta de Hogares de Propósitos Múltiples, 2015; Perú: Encuesta Nacional de Hogares sobre Condiciones de Vida y Pobreza, 2015; Uruguay: Encuesta Continua de Hogares, 2015.

Nota: Los resultados son estadísticamente significativos a nivel de ${ }^{\star \star} 0,01,{ }^{\star} 0,05 y^{\star \star \star} 0,10$.

Los resultados del cuadro 4 indican que, en los siete países, las personas de edad que viven en zonas urbanas tienen más posibilidades de poseer una computadora que las que viven en zonas rurales (de 1,30 más posibilidades en Chile a 6,54 en el Perú). Del mismo modo, la probabilidad de poseer una computadora es mayor entre las personas mayores con niveles de educación más altos y los que han tenido hijos. Por último, las personas mayores pertenecientes a minorías étnicas tienen menos probabilidades de poseer una computadora.

La relación entre la posesión de una computadora y las variables de edad y sexo no es uniforme en los siete países del cuadro 4: mientras que en algunos países las posibilidades de poseer una computadora disminuyen con cada año adicional de edad, en otros aumentan. Los patrones también son variados cuando se efectúa un desglose por sexo: mientras que en el Uruguay los hombres tienen más probabilidades que las mujeres de vivir en un hogar con computadora, en otros países ocurre a la inversa.

Los patrones son más uniformes cuando se examina el uso de Internet por parte de las personas mayores (véase el cuadro 5). A medida que aumenta la edad, la probabilidad de usar Internet disminuye en los cinco países examinados. En tres de los cinco países (Chile, Ecuador y Perú), los hombres tienen más probabilidades que las mujeres de utilizar Internet. Las personas mayores pertenecientes a minorías étnicas tienen menos probabilidad de usar Internet que las personas mayores que no pertenecen a esos grupos en Chile, el Perú y el Uruguay. Como ocurre con la posesión de una computadora, existe una asociación estadísticamente significativa entre la residencia urbana y el uso de Internet entre las personas mayores en la región. Cada año adicional de educación aumenta la probabilidad de uso de Internet. Por último, el hecho de tener hijos en el hogar se asocia a mayores posibilidades de utilizar Internet en uno de los cinco países (Chile), en tanto que esto se asocia a menores probabilidades en el Ecuador y el Uruguay.

En suma, a pesar de los aumentos registrados en los últimos años, la posesión de una computadora y el uso de Internet siguen siendo bajos entre las personas mayores en la región. Sin embargo, la mayoría de esas personas mayores que utilizan Internet la han incorporado a su rutina diaria y acuden a ella principalmente para buscar información y comunicarse. Los factores que más sistemáticamente se asocian con la posesión de una computadora y el uso de Internet son la residencia urbana y el nivel educativo alcanzado. Por otra parte, las personas mayores pertenecientes a minorías étnicas, en particular las poblaciones indígenas, tienen menos probabilidades de tener acceso a una computadora en el hogar y de usar Internet.

La relación entre el uso de las TIC en la región y la educación ha sido documentada en otra investigación (Gutiérrez y Gamboa, 2010) y se puede explicar de dos maneras. En primer lugar, dado 
que el nivel educativo alcanzado es un indicador indirecto del nivel socioeconómico, es probable que las personas con mayor nivel educativo tengan un nivel socioeconómico más alto y, por lo tanto, es más probable que cuenten con los recursos económicos necesarios para acceder a las TIC. También es cierto que el uso de las TIC requiere cierto nivel de alfabetización y conocimientos, de modo que las personas con un nivel educativo más alto son más capaces de realizar estas actividades.

Es factible que la asociación entre la residencia urbana y el uso de las TIC esté relacionada con la mayor disponibilidad de productos tecnológicos y la conexión a Internet más amplia en las ciudades. En los cuatro países que miden el origen étnico, es sistemáticamente menos probable que las personas mayores pertenecientes a minorías étnicas utilicen Internet. Esto coincide con un patrón generalizado de exclusión y marginación de estos grupos, que también puede estar relacionado con cuestiones lingüísticas y culturales.

Una última conclusión es que a medida que aumenta la edad, la probabilidad de uso de Internet disminuye: las personas mayores más jóvenes llevan ventaja en el uso de Internet. La relación entre el uso de las TIC (en particular, poseer una computadora) y tener hijos indica que las generaciones más jóvenes desempeñan un papel decisivo en la introducción y exposición de sus padres a los posibles usos de las TIC. Dicho esto, es evidente que hay un amplio margen para aumentar el acceso y uso de las TIC por parte de las personas mayores en la región.

Aunque se ha escrito mucho acerca de la brecha digital entre generaciones, estos resultados indican que hay otra brecha digital: la existente entre la propia población adulta mayor. La penetración de las TIC está muy concentrada en grupos específicos de personas mayores: las personas con cierto nivel de estudios, que residen en zonas urbanas y no pertenecen a grupos indígenas. Por lo tanto, la difusión de tecnologías parece reproducir otras desigualdades socioeconómicas.

\section{Programas que promueven la inclusión digital de las personas mayores}

Para complementar el panorama presentado en las secciones anteriores, es importante examinar lo que están haciendo los distintos países de la región para cerrar la brecha de la era digital. En esta sección se presentan algunas de las políticas y los programas que se están aplicando para promover la inclusión de las personas mayores mediante el uso de las TIC. El objetivo es proporcionar un panorama inicial de la forma en que en la región se está abordando el problema de la brecha de la era digital. Estas experiencias (o prácticas) se han identificado mediante una búsqueda en Internet de los programas dirigidos a las personas mayores puestos en marcha por diversas instituciones en los distintos países de la región.

Cabe destacar que en algunos instrumentos regionales sobre los derechos de las personas mayores se consagra el derecho de acceso a las $\mathrm{TIC}^{7}$. Por ejemplo, en la Carta de San José sobre los Derechos de las Personas Mayores de América Latina y el Caribe, adoptada por los representantes de los Gobiernos en la tercera Conferencia Regional Intergubernamental sobre el Envejecimiento en América Latina y el Caribe en 2012, se menciona específicamente la necesidad de "impulsar

\footnotetext{
7 Los países de la región adhieren al Plan de Acción Internacional de Madrid sobre el Envejecimiento (2002), que en el “Objetivo 1: Igualdad de oportunidades durante toda la vida en materia de educación permanente, capacitación y readiestramiento, así como de orientación profesional y acceso a servicios de colocación laboral", exhorta a los Gobiernos a "garantizar que todos puedan aprovechar los beneficios de las nuevas tecnologías, en particular de las tecnologías de la información y de las comunicaciones, teniendo en cuenta las necesidades de las mujeres de edad", y en el "Objetivo 2: Utilización plena de las posibilidades y los conocimientos de las personas de todas las edades, reconociendo los beneficios derivados de la mayor experiencia adquirida con la edad" llama a "alentar a las personas de edad que realicen tareas de voluntariado a que aporten sus conocimientos en todas las esferas de actividad, en particular las tecnologías de la información" (Naciones Unidas, 2003).
} 
acciones para garantizar el acceso de las personas mayores a las tecnologías de la información y las comunicaciones, a fin de reducir la brecha tecnológica" (CEPAL, 2012).

Más recientemente, en 2015 los Estados Miembros de la Organización de los Estados Americanos (OEA) aprobaron la Convención Interamericana sobre la Protección de los Derechos Humanos de las Personas Mayores (OEA, 2015), donde se menciona específicamente el acceso a las TIC en relación con el derecho a la educación y el derecho a la accesibilidad y a la movilidad personal. En virtud de la Convención, los Estados parte se comprometen a "promover la educación y formación de la persona mayor en el uso de las nuevas tecnologías de la información y comunicación (TIC) para minimizar la brecha digital, generacional y geográfica e incrementar la integración social y comunitaria" (OEA, 2015) y a "promover el acceso de la persona mayor a los nuevos sistemas y tecnologías de la información y las comunicaciones, incluida Internet, y que estas sean accesibles al menor costo posible" (OEA, 2015).

Además de este marco normativo, desde mediados de la década de 2000, los países de América Latina y el Caribe han adoptado el concepto de las TIC para el desarrollo, por lo que se aprobó el Plan de Acción sobre la Sociedad de la Información de América Latina y el Caribe (eLAC), que subraya la importancia de las TIC como instrumentos de desarrollo económico e inclusión social. En 2005, durante las reuniones preparatorias de la segunda fase de la CMSI, los países de la región acordaron el Plan de Acción eLAC 2007. Los planes subsiguientes -eLAC 2010, eLAC 2015 e eLAC 2018- garantizan la continuidad de esta colaboración.

En la Declaración de Ciudad de México, resultado de la Quinta Conferencia Ministerial sobre la Sociedad de la Información de América Latina y el Caribe, los países de la región renovaron los acuerdos concertados en el marco del proceso eLAC y aprobaron la nueva Agenda digital eLAC 2018, que establece 23 objetivos de política en cinco áreas de acción: i) acceso e infraestructura; ii) economía digital, innovación y competitividad; iii) gobierno electrónico y ciudadanía; iv) desarrollo sostenible e inclusión, y v) gobernanza para la sociedad de la información. A fin de avanzar hacia los objetivos de política establecidos en el marco regional del eLAC para las TIC, varios países de la región han aprobado agendas digitales y en muchas de ellas se menciona específicamente la inclusión de las personas mayores (véase el cuadro 6).

\section{Cuadro 6}

América Latina (países seleccionados): planes y agendas digitales nacionales donde se hace una mención específica a las personas mayores

\begin{tabular}{|c|c|c|}
\hline País & Agenda 0 plan & Menciones y referencias a las personas mayores \\
\hline \multirow{3}{*}{ Costa Rica } & \multirow{3}{*}{$\begin{array}{l}\text { Plan Nacional de Desarrollo de } \\
\text { las Telecomunicaciones 2015- } \\
2021 \text { "Costa Rica: Una sociedad } \\
\text { conectada" }\end{array}$} & $\begin{array}{l}\text { (Los proyectos) deberán ser inclusivos, atendiendo a la población en general, incluidas } \\
\text { las poblaciones que se encuentran en situación de vulnerabilidad (aquellas en } \\
\text { desventaja económica), con énfasis en personas con discapacidad, niños y jóvenes, } \\
\text { personas mayores, pueblos indígenas, jefas de hogar y microempresarias, así como } \\
\text { a las instituciones públicas que los atienden. }\end{array}$ \\
\hline & & $\begin{array}{l}\text { Se garantizará que toda la población (incluidas las personas con discapacidad) pueda } \\
\text { acceder a servicios de radiodifusión de calidad desde el punto de vista técnico, en } \\
\text { igualdad de condiciones y sin discriminación alguna. }\end{array}$ \\
\hline & & $\begin{array}{l}\text { Además, la producción de software y el desarrollo de contenidos y aplicaciones } \\
\text { promoverán la accesibilidad, con miras a ofrecer productos y servicios innovadores. }\end{array}$ \\
\hline Guatemala & $\begin{array}{l}\text { Agenda Nacional de la Sociedad de } \\
\text { la Información y el Conocimiento de } \\
\text { Guatemala }\end{array}$ & $\begin{array}{l}\text { Poner en marcha un sistema de "educación para la vida", con la participación de } \\
\text { personas mayores y personas con discapacidad. }\end{array}$ \\
\hline \multirow{3}{*}{ Honduras } & \multirow{3}{*}{$\begin{array}{l}\text { Agenda Digital de Honduras } 2014- \\
\text { 2018: conectividad, transparencia } \\
\text { y eficiencia }\end{array}$} & $\begin{array}{l}\text { Fomentar la inclusión digital de los pueblos y comunidades indígenas, las personas } \\
\text { con discapacidad y las personas mayores. }\end{array}$ \\
\hline & & $\begin{array}{l}\text { Establecer centros de acceso a Internet de banda ancha para las comunidades } \\
\text { rurales y urbanas, que sean accesibles para todos los usuarios, y la instalación de un } \\
\text { programa informático de lector de pantalla para las personas con discapacidad visual. }\end{array}$ \\
\hline & & Promover la inclusión laboral de las personas con discapacidad mediante el teletrabajo. \\
\hline
\end{tabular}


Cuadro 6 (conclusión)

\begin{tabular}{lll}
\hline País & Agenda o plan & Menciones y referencias a las personas mayores \\
\hline México & $\begin{array}{l}\text { Estrategia Digital Nacional, 2013- } \\
2018\end{array}$ & $\begin{array}{l}\text { Profundizar la Campaña Nacional de Inclusión Digital, con especial énfasis en los } \\
\text { pueblos indígenas, las personas mayores, las personas con discapacidad y los grupos } \\
\text { marginados y que viven en la pobreza extrema. }\end{array}$ \\
\hline
\end{tabular}

La evolución necesaria para avanzar hacia la sociedad de la información y del conocimiento en el Perú debe incluir medidas que aborden de manera adecuada la discapacidad y la diversidad desde la perspectiva de la igualdad de derechos y oportunidades, la no discriminación, la accesibilidad universal y la eliminación de barreras para varios grupos vulnerables.

Plan para el Desarrollo de la Sociedad Esto no se limita a la promoción de políticas para aumentar el acceso a las computadoras en el Perú - Agenda Digital 2.0 e Internet, o asegurar que los puntos de acceso, como los telecentros y los quioscos de Internet públicos estén equipados para acoger a distintos tipos de usuarios, incluidas personas con discapacidad, personas de edad, niños, pueblos indígenas y afrodescendientes, entre otros. También implica la creación de proyectos de creación de capacidad y alfabetización digital, el desarrollo de aplicaciones y contenidos que recojan el multiculturalismo y la identidad, y el abordaje de las cuestiones relacionadas con la discapacidad.

Fuente: Elaboración propia.

Muchas de estas estrategias digitales existen en el marco de leyes que reconocen explícitamente los derechos de las personas mayores a las TIC y, en particular, a Internet (véase el cuadro 7). Sin embargo, resulta evidente que la existencia de estas leyes es una condición necesaria, pero no suficiente, para garantizar el derecho de las personas mayores a las TIC.

\section{Cuadro 7}

América Latina (países seleccionados): leyes nacionales que reconocen los derechos de las personas mayores a las tecnologías de la información y las comunicaciones (TIC)

\begin{tabular}{|c|c|c|}
\hline País & Ley & Mención a las personas mayores \\
\hline Argentina & Ley Argentina Digital (2014) & $\begin{array}{l}\text { Los proveedores de servicios tienen la obligación de garantizar que los grupos } \\
\text { sociales específicos, las personas con discapacidad, entre ellos los usuarios con } \\
\text { problemas graves de visión o discapacidad visual, los hipoacúsicos y los impedidos } \\
\text { del habla, las personas mayores y los usuarios con necesidades sociales especiales } \\
\text { tengan acceso al servicio en condiciones equiparables al resto de los usuarios, } \\
\text { de conformidad con lo establecido en la normativa específica (art. 62, párr. c). }\end{array}$ \\
\hline
\end{tabular}

El contrato de servicios debe garantizar que las personas con discapacidad

Ley General núm. 164

Bolivia (Estado del 8 de abril de 2011, Plurinacional de) sobre telecomunicaciones y tecnologías de la información y las comunicaciones

Brasil Ordenanza núm. 16 (2012)

Ley núm. 1221 de 2008, que establece las normas para la promoción y reglamentación del teletrabajo y otras disposiciones

Colombia

Ley General de

Costa Rica

Telecomunicaciones núm. 8642 tengan un acceso adecuado a los servicios (art. 26, párr. II (3)); los usuarios con discapacidad y las personas de edad tienen derecho de que las telecomunicaciones y la tecnología de la información y las comunicaciones sean accesibles, tal como se especifica en el reglamento de ejecución (art. 54, párr. 18); los proveedores deben facilitar el acceso a las telecomunicaciones y la tecnología de la información y las comunicaciones a los usuarios con discapacidad y las personas mayores, como se especifica en el reglamento de ejecución (art. 59 párr. 14).

Garantizar el acceso a la red de servicios de servicios de TIC a las minorías y los grupos marginados, las personas que viven en la pobreza, los grupos indígenas, las personas con discapacidad, la población afrodescendiente y las personas mayores.

El Ministerio de la Protección Social, dentro de los seis (6) meses siguientes a la promulgación de esta ley, formulará una política pública de incorporación al teletrabajo de la población vulnerable (personas con discapacidad, población en situación de desplazamiento forzado, población en situación de aislamiento geográfico, hogares encabezados por mujeres, prisioneros y personas con amenaza de vida) (art. 3, párr. 1).

Proveer servicios de telecomunicaciones de calidad, oportunos y eficientes, con tarifas asequibles y competitivas, a instituciones y personas con necesidades especiales, incluidos los albergues sociales para niños, las personas de edad, las personas con discapacidad, los pueblos indígenas, las escuelas públicas y los centros de salud pública (art. 32, párr. (c)).

Fuente: Elaboración propia. 
Con respecto al diseño de los programas que promueven el uso de las TIC entre las personas mayores, y que se mencionan a continuación, es importante señalar, en primer lugar, que las prácticas descritas no son exhaustivas ni representativas de lo que se está haciendo en los distintos países de la región, y que tampoco pueden considerarse "mejores prácticas". Solo ofrecen una idea general de algunos de los programas que se encuentran en marcha en la región. En segundo término, lo que se presenta a continuación debe tomarse como una aproximación preliminar, ya que la falta de la información necesaria imposibilitó el examen de aspectos fundamentales de los programas, tales como la cobertura, el rendimiento, los resultados, los efectos y el financiamiento. Estos elementos pueden identificarse como prioridades en futuras investigaciones.

En el cuadro 8 se resumen algunas de las características básicas de los programas de inclusión digital dirigidos a las personas mayores que se encuentran en marcha en la región. En este sentido cabe hacer dos puntualizaciones. La primera es que la inclusión digital entre las personas mayores se promueve ofreciendo acceso a tecnologías digitales y, al mismo tiempo, desarrollando competencias digitales (en particular, las relacionadas con la alfabetización digital) mediante talleres de informática. En su trabajo más reciente, Van Deursen y Van Dijk (2014) sostienen que el concepto de "acceso" es multifacético e incluye cuatro aspectos distintos: la motivación de utilizar computadoras e Internet ("acceso motivacional"), el acceso físico - ya sea público o privado - a computadoras e Internet ("acceso material"), las competencias digitales ("acceso de competencias") y las oportunidades de uso ("acceso de uso"). Según Van Dijk, los problemas de acceso pasan gradualmente del acceso físico al acceso de uso (que, como se mencionó en la sección III, se ha denominado "segunda brecha digital").

\section{Cuadro 8}

América Latina (países seleccionados): ejemplos de programas para la inclusión digital de las personas mayores

\begin{tabular}{|c|c|c|c|c|}
\hline País & Iniciativa & $\begin{array}{l}\text { Período de } \\
\text { ejecución }\end{array}$ & Forma & Organismo ejecutor \\
\hline \multirow[b]{2}{*}{ Argentina } & Programa Postas Digitales ${ }^{\mathrm{a}}$ & & Talleres de informática & Gobierno de la Ciudad de Buenos Aires \\
\hline & $\begin{array}{l}\text { Programa UPAMI (Universidad para } \\
\text { Adultos Mayores Integrados) }\end{array}$ & & $\begin{array}{l}\text { Cursos de alfabetización } \\
\text { tecnológica y digital } \\
\text { para la vida cotidiana }\end{array}$ & $\begin{array}{l}\text { Universidades que ofrecen cursos para } \\
\text { personas mayores y el programa de } \\
\text { atención a las personas mayores }\end{array}$ \\
\hline \multirow{3}{*}{ Costa Rica } & Cursos de tecnología & & $\begin{array}{l}\text { Cursos de informática } \\
\text { básica }\end{array}$ & $\begin{array}{l}\text { Asociación Gerontológica } \\
\text { Costarricense (AGECO) e Instituto } \\
\text { Gerontológico de Formación (IGEF) }\end{array}$ \\
\hline & Programa Ciudadano de Oro & & $\begin{array}{l}\text { Cursos de informática } \\
\text { básica }\end{array}$ & $\begin{array}{l}\text { Consejo Nacional de la Persona } \\
\text { Adulta Mayor (CONAPAM), Caja } \\
\text { Costarricense de Seguro Social y } \\
\text { Universidad Latinoamericana de Ciencia } \\
\text { y Tecnología (ULACIT) de Costa Rica }\end{array}$ \\
\hline & $\begin{array}{l}\text { Proyecto ED-1498: tecnologías } \\
\text { digitales para adultos mayores en el } \\
\text { marco del Programa de Tecnologías } \\
\text { Educativas Avanzadas (PROTEA) }\end{array}$ & 2005 & Cursos por Internet & Universidad de Costa Rica \\
\hline Chile & Chile Mayor Digit@I2.0 & $\begin{array}{l}2013 \text { a la } \\
\text { actualidad }\end{array}$ & $\begin{array}{l}\text { Instalación de Plazas } \\
\text { Digitales Ciudadanas }\end{array}$ & $\begin{array}{l}\text { Servicio Nacional del Adulto Mayor de } \\
\text { Chile y Fundación de Vida Rural de la } \\
\text { Pontificia Universidad Católica de Chile }\end{array}$ \\
\hline \multirow[t]{2}{*}{ México } & $\begin{array}{l}\text { Cursos de educación digital } \\
\text { brindados por la Universidad } \\
\text { Autónoma de Nueva León }\end{array}$ & En desarrollo & $\begin{array}{l}\text { Cursos gratuitos } \\
\text { de informática }\end{array}$ & $\begin{array}{l}\text { Universidad para Adultos } \\
\text { Mayores, como parte de la red de } \\
\text { Universidades de la Tercera Edad }\end{array}$ \\
\hline & Biblioteca digital TELMEX & En desarrollo & Cursos de inclusión digital & $\begin{array}{l}\text { Teléfonos de México (TELMEX) } \\
\text { y Fundación Carlos Slim }\end{array}$ \\
\hline Perú & $\begin{array}{l}\text { Campaña Gratuita de } \\
\text { Alfabetización Digital }\end{array}$ & 2013 & $\begin{array}{l}\text { Cursos de informática } \\
\text { e Internet }\end{array}$ & $\begin{array}{l}\text { Asociación Peruana de } \\
\text { Ingenieros Profesionales }\end{array}$ \\
\hline Uruguay & Plan Ibirapitá & 2015 & $\begin{array}{l}\text { Proporciona tabletas } \\
\text { electrónicas y cursos } \\
\text { básicos a jubilados } \\
\text { y pensionados }\end{array}$ & Plan Ceibal \\
\hline
\end{tabular}

Fuente: Elaboración propia.

a Véase [en línea] http://www.buenosaires.gob.ar/noticias/las-postas-digitales-acercan-los-mayores-las-nuevas-tecnologias. 
Los programas aquí considerados ofrecen "acceso material" para la inclusión digital de las personas mayores en la región. Tal es el caso, por ejemplo, del programa Postas Digitales puesto en marcha por el Gobierno de la Ciudad de Buenos Aires, que tiene por objeto acercar más a las personas mayores a la tecnología digital mediante el establecimiento de centros públicos, equipados con computadoras y conexión a Internet, en distintos barrios. Estos centros también actúan como lugares de reunión donde las personas mayores pueden socializar.

El programa Chile Mayor Digital 2.0 ofrece talleres de alfabetización digital, aunque de una forma algo más amplia que los ejemplos anteriores ${ }^{8}$. La idea es que las personas mayores se familiaricen con plataformas que puedan ayudarlos en la vida diaria y les permitan mantener la comunicación con sus seres queridos, interactuar con grupos de personas de su edad en todo el país a través de las redes sociales y conocer distintos sitios web. El programa también ofrece cursos y seminarios temáticos que tienen por objeto promover el uso de Internet, al informarles sobre las oportunidades que les brindan las redes digitales, por ejemplo, los portales web del gobierno local, donde se incluye información sobre los diferentes programas, talleres y beneficios a los que pueden acceder las personas de edad o que les permiten llevar a cabo tareas administrativas en línea.

Cabe señalar que en esos espacios que ofrecen "acceso material", sobre todo a la población pobre y vulnerable, se da por sentado que las personas mayores tienen la motivación de utilizar computadoras e Internet. Estos espacios tecnológicos se establecen con el fin de desarrollar competencias digitales, en particular las relacionadas con la alfabetización digital. En sentido estricto, y siguiendo el modelo de Van Dijk, la expresión "alfabetización digital" hace referencia a las competencias digitales que están relacionadas con los soportes, o sea, las competencias operativas (conocer las acciones necesarias para operar un soporte digital) y las competencias formales (saber cómo manejar las estructuras formales del soporte: navegación, búsqueda). Algunos de los programas que se encuentran en funcionamiento tratan de ir más allá y desarrollar competencias relacionadas con el contenido 9 .

Por ejemplo, en el marco del programa Postas Digitales se ofrecen talleres de alfabetización digital para personas mayores dos veces por semana durante un período de seis meses. A fin de complementar la capacitación recibida, los participantes reciben una guía de competencias relacionadas con los soportes, donde se incluyen tanto competencias operativas como formales. El programa tiene como finalidad contribuir al compromiso del Gobierno de integrar a 100.000 personas mayores al mundo digital.

Otro ejemplo es el programa Alfabetización digital para el adulto mayor que se ha puesto en marcha en Lima y apunta a personas mayores con poco o ningún conocimiento de las tecnologías de la comunicación ${ }^{10}$. Este programa, que se encuentra en su etapa inicial y cuenta con el patrocinio de la Asociación Peruana de Ingenieros Profesionales, tiene por objeto dar a las personas mayores la oportunidad de aprender competencias digitales relacionadas con los soportes, de modo que puedan utilizar las tecnologías digitales en la vida cotidiana. Al final de la formación, se espera que los participantes puedan utilizar herramientas de Internet, como motores de búsqueda, navegadores, servicios de correo electrónico y blogs o sitios web personales.

\footnotetext{
8 Véase [en línea] http://www.senama.cl/n7035_21-01-2016.html.

9 Las competencias relacionadas con el soporte consideran los detalles técnicos del uso de los soportes (competencias operativas y formales), mientras que las competencias relacionadas con el contenido consideran los aspectos que se refieren al contenido proporcionado por los soportes (información, comunicación, creación de contenido y competencias estratégicas). La distinción tiene un carácter secuencial y condicional. En otras palabras, las competencias son consecutivas y se superponen entre sí. Por ejemplo, poner en práctica competencias relacionadas con el contenido exige dominar competencias relacionadas con los soportes. Véase Van Deursen y Van Dijk (2014, pág. 7).

10 Véase [en línea] http://rpp.pe/lima/actualidad/inician-campana-gratuita-de-alfabetizacion-digital-para-adultos-mayores-noticia -409336 .
} 
En el Uruguay se ha implementado un método distinto para promover la inclusión digital de las personas mayores a través del Plan Ibirapitá, que el Gobierno puso en marcha en 2015 con el fin de complementar los cursos de capacitación en tecnologías digitales brindados por distintas instituciones. En el marco del Plan Ceibal, el programa tiene como finalidad contribuir a la igualdad de acceso al conocimiento y la inclusión social de los jubilados.

A través del Plan Ibirapitá se entregan tabletas electrónicas para introducir a las personas de edad y los jubilados de bajo nivel socioeconómico al mundo digital. Tras una prueba piloto llevada a cabo a mediados de 2015 para evaluar y hacer ajustes en los programas informáticos, comenzó la entrega masiva de los dispositivos, con el objetivo de entregar 100.000 tabletas en 2016. Las tabletas, especialmente diseñadas para ser intuitivas y fáciles de usar (acceso simple, textos e íconos grandes), se entregan durante un taller en el que los beneficiarios aprenden a manejar el equipo y los programas. Para muchos de ellos, este es el primer contacto con un dispositivo electrónico. El taller no solo los familiariza con las principales características de estos artefactos, sino que también les brinda la oportunidad de relacionarse con los compañeros y superar una posible tecnofobia. El contenido del dispositivo se divide en cuatro categorías: salud, entretenimiento, tareas administrativas y comunicación. Según Novaresse (2015), la categoría de salud sería una de las más útiles para los beneficiarios, ya que incluye la aplicación Caléndula que les permite gestionar la ingesta de medicamentos mediante un calendario en el que los usuarios pueden ingresar rutinas personalizadas de medicación. En el sitio web Ibirapitá también se pueden encontrar tutoriales sobre la tecnología ${ }^{11}$. Resulta interesante destacar que el programa incluye una campaña que tiene por objeto ayudar a los hijos y nietos de los beneficiarios a utilizar y adoptar la tecnología.

El segundo aspecto que cabe mencionar es que los programas de inclusión digital para personas mayores en la región se están llevando a cabo a través de diferentes acuerdos institucionales. Por ejemplo, el programa Chile Adulto Mayor Digital 2.0 es administrado por el Servicio Nacional del Adulto Mayor (que es un servicio público), en colaboración con la Fundación de Vida Rural de la Pontificia Universidad Católica de Chile. Esta iniciativa público-privada complementa la agenda digital del Gobierno para reducir la brecha digital en el país. En el programa Plazas Digitales Ciudadanas, diversos organismos públicos y empresas privadas muestran la cantidad de cosas que se pueden hacer a través de Internet para mejorar la calidad de vida de las personas mayores. La iniciativa también requiere la coordinación de los gobiernos nacionales y locales. El programa Postas Digitales es ejecutado por el Gobierno de la Ciudad de Buenos Aires, en coordinación con el Ministerio de Desarrollo Social y la Subsecretaría del Adulto Mayor. Esta es una iniciativa pública que funciona en conexión con organizaciones de la sociedad civil, asociaciones e instituciones que atienden a personas de edad.

En Lima, el programa Alfabetización digital para el adulto mayor ${ }^{12}$ es coordinado por la Asociación Peruana de Ingenieros Profesionales en colaboración con la Universidad de Ciencias y Humanidades (por intermedio de su Facultad de Ingeniería), a través de acuerdos firmados con los gobiernos locales, como ocurrió en el distrito septentrional de Comas. En Costa Rica, el programa Ciudadano de Oro es una iniciativa conjunta de la Universidad Latinoamericana de Ciencia y Tecnología (ULACIT) de Costa Rica, el Consejo Nacional de la Persona Adulta Mayor (CONAPAM) y la Caja Costarricense de Seguro Social. Este programa tiene por objeto crear una cultura de respeto por las personas de 65 años o más, en reconocimiento al esfuerzo y el trabajo realizado a lo largo de su vida, y ofrece diversas prestaciones gratuitas, descuentos y un trato preferencial a las personas mayores que tengan la tarjeta que los identifica como "ciudadanos de oro". Entre los beneficios se incluyen cursos de alfabetización digital que buscan aumentar el contacto social, la independencia y el desarrollo de las personas de edad.

\footnotetext{
${ }^{11}$ Véase [en línea] http://ibirapita.org.uy.

12 Véase [en línea] http://rpp.pe/lima/actualidad/inician-campana-gratuita-de-alfabetizacion-digital-para-adultos-mayores-noticia $-409336$
} 
En suma, se están explorando diversas modalidades institucionales para aplicar programas de desarrollo de competencias digitales para la inclusión social de la población de edad avanzada. Sin embargo, los países de la región deben redoblar los esfuerzos para seguir promoviendo el uso de los medios digitales por parte de las personas mayores. Esos esfuerzos deberían, al menos, tener en cuenta los siguientes elementos:

1. Fortalecer la coordinación entre las distintas entidades del sector público, el sector privado y la sociedad civil que organizan programas para promover el uso de las TIC entre las personas mayores, a fin de asegurar que los programas se potencien entre sí.

2. Promover un desarrollo intergeneracional de competencias, de modo que las generaciones más jóvenes ayuden a las personas de edad a familiarizarse con las herramientas digitales que les sean útiles.

3. Fomentar oportunidades de capacitación entre pares, donde las personas mayores que participan activamente en la sociedad digital ayuden a capacitar a las personas de edad que aún no se hayan acercado a las tecnologías digitales (como sucede en el Plan Ibirapitá).

4. Diseñar aplicaciones u otras herramientas tecnológicas que respondan directamente a las necesidades de las personas mayores y que puedan fomentar su integración en la sociedad y crear conciencia sobre estas tecnologías entre las personas mayores.

5. Ampliar el acceso de las personas mayores a Internet en el hogar o a través de dispositivos móviles, en particular para las personas que residen en zonas rurales, las pertenecientes a grupos indígenas y las de bajo nivel socioeconómico.

6. Mejorar los datos sobre el uso de las TIC a nivel individual, ya que, como se indica en el presente análisis, pocos países de la región cuentan con datos que puedan utilizarse para medir el uso de las TIC entre las personas mayores, lo que hace difícil determinar patrones y supervisar políticas.

7. Utilizar también datos cualitativos sería ideal, ya que estos podrían ayudar a comprender mejor cuáles son las barreras y los factores que promueven el uso de las TIC entre las personas mayores en América Latina y el Caribe, así como proporcionar información sobre las cuestiones más relevantes que condicionan el uso de estas tecnologías por parte de esta población (como los bajos niveles de alfabetización, los formatos inaccesibles, el costo, la falta de familiaridad y las percepciones individuales de las TIC).

8. Promover una mayor participación de las personas de edad en el desarrollo de las TIC, a fin de que estas herramientas satisfagan mejor sus necesidades, y alentar la participación en la elaboración de planes y estrategias para ampliar el acceso y uso de las TIC entre las personas mayores.

\section{Conclusiones}

En este artículo se ofrece un panorama regional del uso de las TIC entre las personas mayores, un tema que hasta el momento no se ha analizado en profundidad, pese a su importancia en las sociedades que envejecen. Se proporcionan valiosos datos para orientar la formulación de políticas y el diseño de programas, así como recomendaciones de política concretas para ampliar el acceso de las personas mayores de la región a las TIC y favorecer así su inclusión. A pesar de esta importante contribución, hay que tener en cuenta algunas limitaciones. En 2014, por ejemplo, el 14,9\% de los usuarios en América Latina preferían acceder a Internet mediante teléfonos móviles o tabletas en lugar de hacerlo a través de una computadora personal (CEPAL, 2016b). Debido a las fuentes de 
los datos que se utilizan en el presente estudio, no ha sido posible estudiar este tipo de uso de Internet. Los autores también se vieron limitados por la escasa cantidad de encuestas de hogares en la región que incluyen módulos de TIC. Si bien se han identificado ciertos patrones comunes entre los distintos países, dada la naturaleza sumamente heterogénea de América Latina, es importante tener en cuenta las características específicas de cada país y considerar que los datos que aquí se presentan posiblemente no se apliquen a todos los contextos. Por último, el hecho de que en el estudio se consideren sobre todo iniciativas del sector público (y algunas de la sociedad civil) que promueven el uso de las TIC entre las personas mayores, aunque está claro que el sector privado también cumple un papel fundamental, puede constituir un defecto metodológico.

A pesar de estas limitaciones, el presente estudio supone una importante contribución. En primer lugar, los resultados confirman la existencia de una marcada brecha de la era digital, no solo entre los países, sino también dentro de ellos. Si bien el uso de Internet ha aumentado en todos los países entre las personas de 60 años o más, sus niveles de uso siguen siendo bastante bajos si se comparan con los de los grupos etarios de 15 a 29 años y de 30 a 59 años. Otra conclusión interesante es que, si bien muchas personas mayores en la región viven en hogares con acceso a Internet, un gran porcentaje de ellos no la utilizan. Esto indica que el acceso no es el único factor determinante en la utilización de las TIC por parte de las personas mayores, sino que también son necesarias la motivación y las competencias, en otras palabras, el deseo y la capacidad de aprovechar estos instrumentos. La falta de conocimiento sobre la manera en que estas herramientas pueden satisfacer las necesidades cotidianas puede ser una barrera importante para que las personas mayores usen las TIC. Por lo tanto, es importante generar conciencia acerca de los posibles beneficios de utilizar estas tecnologías y desarrollar competencias entre las personas mayores y las personas cercanas a ellos.

Los resultados de este análisis también corroboran otros estudios previos donde se da cuenta de que el acceso de los hogares a las TIC en América Latina está determinado por la disponibilidad de infraestructura y otras variables económicas, sociales y demográficas (como la ubicación del hogar) (CEPAL, 2016b).

Ciertos grupos sociales también están quedando excluidos de la revolución digital en curso en la región. Como se muestra en este análisis, en igualdad de condiciones, las personas mayores pertenecientes a grupos indígenas tienen menos probabilidades de utilizar Internet que los no indígenas. Por lo tanto, debe tenerse en cuenta que si bien las TIC pueden contribuir a reducir las desigualdades sociales, la inequidad que hoy se registra en el acceso a estas tecnologías puede exacerbar estas desigualdades: unos cosechan los beneficios mientras que otros se quedan atrás.

Con la aprobación de la Agenda 2030 para el Desarrollo Sostenible, todos los países de América Latina y el Caribe se comprometieron a no dejar a nadie atrás. Esto supone, entre otras cosas, adoptar medidas decisivas para reducir las persistentes disparidades que afectan a la región. La brecha digital entre las distintas generaciones y entre la misma población adulta mayor es motivo de preocupación, ya que podría ampliar las brechas que deberían reducirse. 


\section{Bibliografía}

Abusleme, M. T. y otros (2014), Inclusión y exclusión social de las personas mayores en Chile, Santiago, Servicio Nacional del Adulto Mayor (SENAMA)/Facultad de Ciencias Sociales (FACSO) de la Universidad de Chile/Facultad Latinoamericana de Ciencias Sociales (FLACSO)-Chile.

Andreasson, K. (ed.) (2015), Digital Divides: the New Challenges and Opportunities of e-Inclusion, Boca Raton, CRC Press.

Balboni, M., S. Rovira y S. Vergara (eds.) (2011), ICT in Latin America: A Microdata Analysis (LC/R.2172), Santiago, Comisión Económica para América Latina y el Caribe (CEPAL).

Boonaert, T. y N. Vettenberg (2011), "Young people's internet use: divided or diversified?", Childhood, vol. 18, $N^{\circ} 1$, SAGE.

Camacho, K. (2001), "Evaluating the impact of the Internet in civil society organizations of Central America: a summary of a research framework", Fundación Acceso [en línea] http://www.acceso.or.cr/publica/ telecom/frmwkENG.shtml.

Castaño, C. (2008), "La primera y la segunda brecha digital”, La segunda brecha digital, C. Castaño (coord.), Madrid, Cátedra.

CEPAL (Comisión Económica para América Latina y el Caribe) (2016a), La matriz de la desigualdad social en América Latina (LC/G.2690(MDS.1/2)), Santiago.

(2016b), La nueva revolución digital: de la Internet del consumo a la Internet de la producción (LC/L.4029/ Rev.1), Santiago.

(2012), Carta de San José sobre los Derechos de las Personas Mayores de América Latina y el Caribe (LC/G.2537), Santiago [en línea] https://repositorio.cepal.org/bitstream/handle/11362/21534/S2012896_ es. pdf? sequence $=1$ \&isAllowed $=y$.

_(2007), Informe sobre la aplicación de la Estrategia Regional de Implementación para América Latina y el Caribe del Plan de Acción Internacional de Madrid sobre el Envejecimiento (LC/L.2749(CRE-2/3)), Santiago.

CMSI (Cumbre Mundial sobre la Sociedad de la Información) (2016), "WSIS background" [en línea] https:// www.itu.int/net4/wsis/forum/2016/About/Background.

Elwick, A. y otros (2013), Beyond the Digital Divide: Young People and ICT, CfBT Education Trust [en línea] https://www.educationdevelopmenttrust.com/ /media/EDT/Reports/Research/2013/r-beyond-the-digitaldivide-perspective-2013.pdf.

Gutiérrez, L. H. y L. E. Gamboa (2010), "Determinants of ICT usage among low-income groups in Colombia, Mexico, and Peru", The Information Society, vol. 26, № 5, Taylor \& Francis.

Huenchuan, S. (2013), "Perspectivas globales sobre la protección de los derechos humanos de las personas mayores, 2007-2013", Documentos de Proyectos (LC/W.566), Santiago, Comisión Económica para América Latina y el Caribe (CEPAL).

Naciones Unidas (2015), World Population Prospects. The 2015 Revision (ESA/P/WP.241), Nueva York. (2003), Declaración Política y Plan de Acción Internacional de Madrid sobre el Envejecimiento, Nueva York [en línea] https://www.un.org/esa/socdev/documents/ageing/MIPAA/political-declaration-sp.pdf.

Novaresse, C. (2015), "Así funcionan las tabletas para jubilados" [en línea] https://www.cromo.com.uy/asifuncionan-las-tabletas-jubilados-n654160.

OEA (Organización de los Estados Americanos) (2015), "Convención Interamericana sobre la Protección de los Derechos Humanos de las Personas Mayores" [en línea] http://www.oas.org/es/sla/ddi/tratados_ multilaterales_interamericanos_A-70_derechos_humanos_personas_mayores.asp.

OMS (Organización Mundial de la Salud) (2002), Active Ageing: A Policy Framework [en línea] http://www. who.int/ageing/publications/active_ageing/en/.

Piscitelli, A. (2009), Nativos digitales: dieta cognitiva, inteligencia colectiva y arquitecturas de la participación, Buenos Aires, Santillana.

Prensky, M. (2001), "Digital natives, digital immigrants", On the Horizon, vol. 9 , № 5 [en línea] http://www. marcprensky.com/writing/Prensky\%20-\%20Digital\%20Natives,\%20Digital\%2Olmmigrants\%20-\%20 Part1.pdf. 
Selwyn, N. (2004), "Reconsidering political and popular understandings of the digital divide", New Media Society, vol. 6, № 3, SAGE.

- (2003), "Apart from technology: understanding people's non-use of information and communication technologies in everyday life", Technology in Society, vol. 25, No 1, Amsterdam, Elsevier.

Selwyn, N. y K. Facer (2007), Beyond the Digital Divide: Rethinking Digital Inclusion for the 21st Century, Futurelab [en línea] https://www.nfer.ac.uk/publications/FUTL55.

Van Deursen, A. y J. van Dijk (2014), Digital Skills: Unlocking the Information Society, Basingstoke, Palgrave Macmillan. 


\section{Anexo A1}

\section{Cuadro A1.1}

América Latina (países seleccionados): características de las personas mayores que usan tecnologías de la información y las comunicaciones (TIC)

(En porcentajes y años)

\begin{tabular}{|c|c|c|c|c|c|c|c|c|c|}
\hline & \multirow{2}{*}{$\begin{array}{l}\text { Edad media } \\
\text { (en años) }\end{array}$} & \multirow{2}{*}{$\begin{array}{c}\text { Hombre } \\
\text { (en porcentajes) }\end{array}$} & \multirow{2}{*}{$\begin{array}{c}\text { Urbana } \\
\text { (en porcentajes) }\end{array}$} & \multirow{2}{*}{$\begin{array}{l}\text { Educación } \\
\text { promedio } \\
\text { (en años) }\end{array}$} & \multirow{2}{*}{$\begin{array}{l}\text { Origen étnico } \\
\text { indígena } \\
\text { (en porcentajes) }\end{array}$} & \multicolumn{4}{|c|}{$\begin{array}{c}\text { Estado civil } \\
\text { (en porcentajes) }\end{array}$} \\
\hline & & & & & & Casado & Soltero & Viudo & Divorciado \\
\hline Chile & 70,8 & 42,7 & 85,3 & 8,2 & 6,0 & 56,9 & 22,7 & 2,0 & 6,7 \\
\hline Ecuador & 70,5 & 47,6 & 65,3 & 5,9 & 14,6 & 58,2 & 7,3 & 22,6 & 12,0 \\
\hline El Salvador & 71,1 & 45,0 & 65,5 & 4,1 & & 50,2 & 7,3 & 26,7 & 15,8 \\
\hline Honduras & 70,2 & 46,1 & 56,9 & 4,7 & & 56,4 & 19,2 & 18,6 & 5,9 \\
\hline México & 70,3 & 46,1 & & & & & & & \\
\hline Paraguay & 69,8 & 48,4 & 59,5 & 5,7 & & 59,5 & 11,6 & 22,5 & 6,4 \\
\hline Perú & 70,8 & 46,7 & 75,2 & 6,2 & 49,1 & 60,9 & 5,3 & 23,8 & 10,1 \\
\hline Uruguay & 71,6 & 42,0 & 94,3 & 7,7 & 7,1 & 56,3 & 4,7 & 24,9 & 10,8 \\
\hline
\end{tabular}

Fuente: Chile: Encuesta de Caracterización Socioeconómica Nacional (CASEN), 2015; Ecuador: Encuesta Nacional de Empleo, Desempleo y Subempleo en el área urbana y rural, 2015; El Salvador: Encuesta de Hogares de Propósitos Múltiples, 2015; Honduras: Encuesta Permanente de Hogares de Propósitos Múltiples, 2015; México: Módulo sobre Disponibilidad y Uso de Tecnologías de la Información en los Hogares (MODUTIH), 2014; Paraguay: Encuesta Permanente de Hogares, 2015; Perú: Encuesta Nacional de Hogares sobre Condiciones de Vida y Pobreza, 2015; Uruguay: Encuesta Continua de Hogares, 2015. 